\title{
Labor Reallocation, Employment, and Earnings: Vector Autoregression Evidence
}

by

\author{
Henry R. Hyatt \\ U.S. Census Bureau
}

Tucker S. McElroy

U.S. Census Bureau

CES 17-11

January, 2017

The research program of the Center for Economic Studies (CES) produces a wide range of economic analyses to improve the statistical programs of the U.S. Census Bureau. Many of these analyses take the form of CES research papers. The papers have not undergone the review accorded Census Bureau publications and no endorsement should be inferred. Any opinions and conclusions expressed herein are those of the author(s) and do not necessarily represent the views of the U.S. Census Bureau. All results have been reviewed to ensure that no confidential information is disclosed. Republication in whole or part must be cleared with the authors.

To obtain information about the series, see www.census.gov/ces or contact J. David Brown, Editor, Discussion Papers, U.S. Census Bureau, Center for Economic Studies 5K034A, 4600 Silver Hill Road, Washington, DC 20233, CES.Papers.List@census.gov. To subscribe to the series, please click here. 


\begin{abstract}
An increasing number of data sources have measured the components of reallocation of jobs across employers and workers across jobs. Whether and how job reallocation across employers and excess worker "churn" affect other measures of the health of the U.S. economy remains an open question. In this paper, we present time series evidence for the U.S. 1993-2013 and consider the relationship between labor reallocation, employment, and earnings using a vector autoregression (VAR) framework. We find that labor market churn Granger-causes higher employment and lower unemployment, while job destruction does the opposite. We also find more limited evidence that churn and job destruction predict increased earnings, although this is not found for all earnings measures.
\end{abstract}

\footnotetext{
${ }^{*}$ This report is released to inform interested parties of research and to encourage discussion. Any opinions or conclusions expressed herein, including on statistical issues, are those of the authors and not necessarily those of the U.S. Census Bureau. We are grateful to James Spletzer for many helpful discussions as we started the project. We thank Eric V. Slud and Lawrence F. Warren for helpful comments and suggestions, as well as Alexandria Zhang for assistance. Center for Economic Studies, U.S. Census Bureau, 4600 Silver Hill Road, Washington, D.C. 20233-9100, henry.r.hyatt@census.gov Center for Statistical Research and Methodology, U.S. Census Bureau, 4600 Silver Hill Road, Washington, D.C. 20233-9100, tucker.s.mcelroy@census.gov
} 


\section{Introduction}

The U.S. labor market exhibits a considerable amount of job and worker reallocation. Employers are continually entering and exiting the market, which is itself expanding and contracting, while workers are at the same time beginning and ending jobs. The rate at which these transitions occur have many well-known cyclical properties. During expansions, job creation rises as new businesses enter and incumbents expand, whereas during contractions job destruction rises as businesses exit and incumbents contract. Hires and separations in the U.S. economy occur much more frequently than is necessary to reallocate jobs across employers. Excess reallocation, called labor market churn, is procyclical and therefore increases along with other measures of the health of the labor market. ${ }^{1}$ But whether and how job reallocation and churn affect other labor market outcomes and the economy as a whole remains unknown.

We address that question in this paper. We present time series evidence for the U.S. 19932013 and consider the relationship between labor reallocation, employment, and earnings in a vector autoregressive (VAR) model. This framework allows us to measure when movements in aggregate measures are immediately followed by changes in other aggregate measures, and assess to what extent one set of variables impacts the forecast performance of other variables. When such a forecast impact is non-negligible, the variable is said to Granger (1969) cause movements in another variable. We find substantial evidence that labor market churn Granger-causes higher employment and lower unemployment, while job destruction does the opposite. We also find some more limited evidence that churn and job destruction predict increased earnings rates, although this is not found for all earnings measures.

The effects of labor reallocation are of some concern, because the U.S. labor market has exhibited less reallocation during the past two decades. Hyatt and Spletzer (2013) document declining employment dynamics in a variety of commonly used data series, and show doubledigit percent declines in most measures of employment reallocation for the years 1998-2012. There is speculation that declining employment dynamics may slow economic growth. The implicit assumption here is that employment dynamics are, on net, beneficial: that worker reallocation moves people to better jobs and job reallocation moves workers toward higher

${ }^{1}$ Churn is sometimes called "excess employment reallocation." See Burgess, Lane, and Stevens (2000) and Abowd and Vilhuber (2011). 
productivity firms. Lazear and Spletzer (2012) estimate that decreased levels of labor market churn during the Great Recession led to a reduction of two-fifths of a percentage point in annual GDP. Faberman and Justiniano (2015) show that earnings growth and inflation are procyclical and have similar aggregate trends to the quit rate, which roughly corresponds to labor market churn. Davis and Haltiwanger (2014) find that reduced fluidity lowers employment rates, especially for younger and less educated workers. Policymakers have proposed that labor market flows provide information about the amount of slack in the labor market. ${ }^{2}$

There are many proposed mechanisms through which reduced churn may lead to a reduction in health of the labor market. First, reduced churn may lead to reduced employment. It may signal that demand is lower and that employment growth will be lower as a result. This has been formalized in Barlevy (2002), who estimates a model in which lower labor demand leads to lower employment, reduced churn, and worse matches. Lower churn may also lead to lower earnings. ${ }^{3}$ Workers tend to receive earnings increases when switching jobs - see Topel and Ward (1992), who show that one third of earnings growth for young men can be accounted for by the earnings changes associated with job change. Also, a lower offer arrival rate may lower worker bargaining power, as in Cahuc, Postel-Vinay, and Robin (2006). Evidence for a procyclical job ladder that reallocates workers from lower-paying to higherpaying firms, industries, and occupations has been documented in Kahn and McEntarfer (2014), Haltiwanger, Hyatt, and McEntarfer (2015), and Cairo, Hyatt, and Zhao (2015).

There has been little systematic empirical work regarding whether the reduced levels of labor market dynamics influence other key labor market measures such as employment and earnings. We know that employment sagged during the 2000s, and that real earnings stagnated during the same period (Acemoglu et al. 2015). Is it coincidence that these shifts in trend occured at the same time that employment dynamics began to decline? In this paper, we use standard time series estimation methods to determine whether declining

${ }^{2}$ Yellen (2014) notes that labor market flows provide information on the amount of slack in the labor market, and slack is important in judging where the economy is with regard to full employment. The Economic Report of the President (2015) notes that lower rates of labor market fluidity may lead to reduced earnings growth through two channels - a reduction due to fewer job changes, and reduced bargaining power on the current job as the threat of changing jobs decreases.

${ }^{3}$ Hahn, Hyatt, and Janicki (2016) implement a variant of the Topel and Ward (1992) measurement strategy on matched employer-employee data for recent decades in the U.S. and find that the direct contribution of the earnings gains associated with job-to-job flows is procyclical. 
employment dynamics Granger-cause employment and earnings trends. This means that we are interested in non-contemporaneous relationships between variables. As we find that the best fitting model is a VAR(1), or a model with only one lag, our estimates indicate the extent to which a movement in one variable is followed by a movement in another variable in the next quarter. Our analysis is purely empirical, in that we do not attempt to determine why, or through what mechanism, declining dynamics might influence earnings and employment.

In this paper, we take advantage of new data sources that permit the measurement of labor market churn for recent decades. Specifically, we use national-level data from the Quarterly Workforce Indicators from the Longitudinal Employer-Household Dynamics (LEHD) program at the U.S. Census Bureau using the method proposed by Abowd and Vilhuber (2011). These provide data on employment reallocation, specifically, hires, separations, job creation, job destruction for 1993.Q2 to 2013.Q4. In order to test whether there is any Granger-causal relationship between labor reallocation rates and employment and earnings, we fit VAR models and test whether control variables can safely be omitted. This variable selection technique is a novel method for assessing whether or not variables in the VAR affect each other on the basis of overall model fit.

We have two primary dependent variables of interest. We are interested in whether churn Granger-causes increased employment (or lower unemployment) and increased earnings. We rely on the Current Population Survey (CPS) and the LEHD data for measures of employment. For earnings, there are more reference points available, and considerably less agreement between earnings measures. We use two commonly used data sources on the earnings level: the Current Employment Statistics survey (CES) and the CPS.

We begin this paper with a description of our data. Much of our focus is on the LEHD quarterly data, which provides measures of hires, separations, job creation, job destruction, employment, and earnings from one single source. After a description of the econometric methodology, we present the empirical results, which are as follows. There is a great degree of consistency between different measures of employment and unemployment for the U.S., and, consequently, we find substantial similarity in our results in the LEHD employment series and the CPS unemployment series. Labor market churn is found to Granger-cause increased employment and lower unemployment, while job destruction does the opposite. In earnings, there is more diversity in the trends in each series, and we find different patterns 
of Granger-causality across different data series. We find that labor market churn Grangercauses increased earnings in the LEHD average monthly earnings series but not that of the CPS median weekly earnings of full-time employees or CES average weekly earnings of production and non-supervisory employees. We find that job destruction Granger-causes increased earnings in the LEHD earnings and CPS but not the CES.

\section{The Data}

\section{$2.1 \quad$ Economic Measures}

We study quarterly time series of hires, separations, job creation, and job destruction at a national level for 1993.Q2 through 2013.Q4. We are interested in the impact of these variables on earnings data, as well as employment and unemployment figures. Of secondary interest are the variables of real GDP and the price level, which are included as controls ${ }^{4}$. A derivative series, known as churn, is defined as the difference between hires and job creation. All the quarterly data have seasonal, trend, and cycle dynamics. In what follows, we provide an overview of all economic measures used in the analysis. For additional details and specific steps in the data preparation see Appendix A.

\subsubsection{Labor Reallocation Measures}

Definitions of labor reallocation measures are as follows for a particular time interval $t$ (year, month, etc.). We can count the number of individuals employed at the beginning of that quarter $\left(\right.$ empbeg $\left._{t}\right)$ and also at the end of that quarter $\left(\right.$ empend $\left._{t}\right)$. Hires $\left(\right.$ hires $\left._{t}\right)$ are new employer-employee relationships (i.e., did not exist in time $t-1)$. Separations $\left(\right.$ seps $\left._{t}\right)$ are employer-employee relationships that end in period $t$ (i.e., do not exist in time $t+1$ ). Job creation $\left(j c_{t}\right)$ measures the net hires at establishments that enter (all employees that appear in time $t$, i.e., all hires) or gain employment (i.e., hires minus separations). Job destruction $\left(j d_{t}\right)$ measures the net separations at establishments that exit (all employees that appear in time $t$ separate) or contract (i.e., separations minus hires).

${ }^{4}$ Omitting relevant variables from a VAR model may indicate a direct causal relationship between two variables that otherwise would be described indirectly through the action of the omitted variable. 
These four labor series exhibit strong seasonal movements, which mask the underlying trend and cyclical movements; for this reason, we will focus upon seasonally adjusted data where additive outliers have been removed. Before discussing these procedures, we note that these labor series have an element of redundancy - the following identity is a stylized economic fact ${ }^{5}$, and moreover is numerically true (up to rounding errors):

$$
\text { hires }_{t}-\operatorname{seps}_{t}=j c_{t}-j d_{t}=\text { empend }_{t}-\text { empbeg }_{t}
$$

for all times $t$. Given the empirical validity of (1), it would be a fallacy to include all the four variables for hires, separations, job creation, and job destruction in a model, as this would generate multicollinearity problems and yield a nonidentifiable model ${ }^{6}$. Now, with the definition of churn $\left(\right.$ churn $\left._{t}\right)$ as

$$
\operatorname{churn}_{t}=\text { hires }_{t}-j c_{t},
$$

it follows from (1) and (2) that

$$
\operatorname{seps}_{t}=j d_{t}+\operatorname{churn}_{t}
$$

So (3) indicates that separations should be eliminated from the data; we will henceforth focus upon churn, job creation, and job destruction. ${ }^{7}$

${ }^{5}$ See Burgess, Lane, and Stevens (2000), Davis, Faberman, and Haltiwanger (2006), and Lazear and Spletzer (2012).

${ }^{6}$ In the setting of a stationary VAR process, such multicollinearity would manifest through a coefficient matrix of reduced rank.

${ }^{7}$ Hires and separations are defined at the establishment level in the LEHD and so within-company transfers across establishments in principle contribute to churn. However, among U.S. states, only Minnesota requires employers to report such transfers, so within-company transfers are best measured in the LEHD data when a worker's transfer is across establishments that have different Unemployment Insurance accounts, for example when a transfer is across states. Difficulty in measuirng within-company transfers means that establishmentlevel churn is slightly understated in the LEHD data. 


\subsubsection{Employment and Unemployment}

We are chiefly interested in the impact of these three variables upon earnings, employment, and unemployment. ${ }^{8}$ Following Abowd and Vilhuber (2011), employment is from the LEHD Quarterly Workforce Indicators and is defined as

$$
\operatorname{emp}_{t}=\frac{\text { empend }_{t}+\text { empbeg }_{t}}{2}
$$

The unemployment rate comes from the Bureau of Labor Statistics, and measures the frequency with which people age 16 and over are available for work and have looked for work in the last four weeks. The denominator for this rate is the sum of those people age 16 and over who are employed plus those who are unemployed (i.e., the labor force).

\subsubsection{Earnings}

Finding a suitable proxy variable for the concept of earnings presents several viable choices. Economists tend to focus attention on real earnings, defined as nominal earnings normalized by the inflation rate. The LEHD database offers one such real earnings series, but we also consider sources from the CES and the CPS as well, as sensitivity checks for our analysis. These data sources have substantial differences that have been the subject of many studies, discussed in Abraham, Spletzer, and Stewart (1998) and Champagne and Kurman (2013). We also wish to highlight trends in earnings in the LEHD data, which is an administrative records source. Average earnings in this data source have recently been considered by Barth et al. (2014), Spletzer (2014), and Hyatt and Spletzer (2016). There are considerable differences between these different earnings series.

\subsubsection{Other Aggregate Measures}

In addition we consider the variables of the price level and real Gross Domestic Product (GDP); see Appendix $\mathrm{A}^{9}$. The price level is used to convert nominal GDP and earnings into

${ }^{8}$ Note that employment and unemployment rates do not sum to unity, because there is a third component - those persons not in the labor force.

${ }^{9}$ It's quite plausible a priori that these two variables have an impact on earnings and/or employment, potentially affecting these quantities through tertiary variables. 
real terms, and is also included in some VAR specifications as a control variable.

\subsection{Signal Extraction}

Our main dataset of interest consists of churn, job creation, job destruction, earnings, and employment. Other variables of secondary interest are the unemployment rate, the price level, and GDP, which we utilize to examine the robustness of the identified economic relationships. While it is possible to consider data frequencies other than quarterly, such as annual and monthly, we have found that VAR analyses for these alternative data are unhelpful, and are therefore excluded ${ }^{10}$. All these time series are available unto the end of 2013 . Of course, each series is subject to anomalous effects, generating extreme values and idiosyncratic noise. Therefore, our models will involve standard techniques to identify and control for level shifts, seasonality, and other data anomalies. The principal goal of analysis is to determine whether certain variables Granger-cause other variables, and we apply standard VAR methods (Lütkepohl, 2007) to our adjusted datasets.

\subsubsection{Seasonal Adjustment}

The raw data must be seasonally adjusted, because we are not interested in Granger-causality of seasonal movements. Moreover, we argue that the data should be detrended, so that longterm co-movements do not produce spurious correlations between the variables. Ideally, a single latent component model involving seasonal, trend, and cyclical structures should be fitted. However, we are able to obtain adequate and statistically defensible results by proceeding in three stages. First, we seasonally adjust each series individually (and account for outliers and other fixed effects) using X-13ARIMA-SEATS (U.S. Census Bureau, 2016). Second, we remove long-term trend movements via application of the HP high-pass filter. The output can be viewed as the stationary cyclical component (although idiosyncratic noise will also be included). Third, we model this estimated cycle with a VAR(1) model. We next provide a few details on each step.

${ }^{10}$ All available data are measurements, representing useful proxies for underlying economic concepts; the monthly and annual vintages of the above variables are compiled from different sources in some cases, and utilizing different measurement methodologies. As a result, the univariate time series structure of each is quite different across frequencies, violating the premise that higher frequency measurements can be flowaggregated to obtain accurate (or exact) lower frequency quantities. 
Univariate seasonal adjustment is recognized to be adequate in most cases, with little added benefit to performing multivariate seasonal adjustment. We proceed to specify Reg ARIMA (Autoregressive Integrated Moving Average with Regression effects) for each of the eight series, allowing the X-13ARIMA-SEATS software to automatically determine a BoxCox transform, identify additive outliers and level shifts, test for trading day effects, and select a seasonal ARIMA model from a suite of candidates. Details about these models and procedures, as well as the software X-13ARIMA-SEATS, can be found in U.S Census Bureau (2016). The identified model is used to forecast-extend the data, to which the X-11 moving average filters are applied. The resulting seasonal adjustment was checked for adequacy via several diagnostics.

The seasonally adjusted data, rescaled in some cases, are graphed in Figure 1. All residual diagnostics (i.e., Ljung-Box statistics) for the RegARIMA models were satisfactory, and autocorrelation diagnostics indicate that all dynamic seasonality was removed. Consistent with the evidence in Hyatt and Spletzer (2013), the labor reallocation series appear to have a trend decline. Job creation is distinctly lower in the recession years of 2008 and 2009, when job destruction is distinctly higher. Labor market churn has a clear "stair-step" pattern with declines in the labor market downturns associated with the 2001 and 2007-2009 recessions and tepid rises afterwards. Earnings increases during the late 1990s, then is constant and mildly procyclical after the year 2000. Employment shows a similar pattern to earnings, with a sustained rise followed by a procyclical but essentially flat series after the year 2000 . Unemployment rises when employment is lower. Finally, the price level and GDP expand throughout the 1990s and 2000s, with a noticeable downturn in each during the recession years 2008 and 2009 .

\subsubsection{Trend}

The HP filter is quite popular among econometricians for decomposing seasonally adjusted data into long-term trend and business cycle. For quarterly data, the canonical choice of 1/1600 for the signal-to-noise ratio parameter is recommended (Hodrick and Prescott, 1997). Failure to remove strong trend effects in the data will drive the VAR parameters toward the region of nonstationarity, as some of the seasonally adjusted series resemble a random walk, 
or autoregression with strong persistency. Of course, choice of the signal to signal-to-noise ratio (SNR) will have an impact on the cycle that is obtained: an SNR of zero will yield a straight line trend, while an SNR of infinity yields a cycle equal to zero identically. ${ }^{11}$ Our choice of 1/1600 for the finite-sample HP filter is ad hoc, but at least is consistent with current practice, and yields sensible results. ${ }^{12}$

The residual cycle estimates - which have mean zero, due to the HP-detrending - are given in Figure 2. These show clear co-movements among series; also observe the counteracting movements of employment $\left(e m p_{t}\right)$ and unemployment $\left(u n e m p_{t}\right)^{13}$. It is precisely these series that enter directly into our VAR model, but there are a few things we can learn from these graphs directly. First, churn and GDP are remarkably similar after detrending. Second, the detrended employment and unemployment series are mirror images of each other, which is expected since the populace can be subdivided into three mutually exclusive categories: employed, unemployed, and not in the labor force. Finally, LEHD earnings appears procyclical and rather similar to churn and GDP ${ }^{14}$.

\section{$3 \quad$ Vector Autoregression Strategy}

\subsection{Standard (Unrestricted) VAR Estimation}

Having obtained the trend residual, or cycle, we proceed to modeling via the VAR methodology. ${ }^{15}$ Standard diagnostics, such as residual autocorrelation plots, were utilized to assess goodness of fit, and indicated the adequacy of the order one VAR for these series.

It's important to assess the significance of the VAR coefficients, which can be done by utilizing their estimated standard errors, as discussed in Lütkepohl (2007). Grangercausality for a VAR model reduces to examination of the nonzero coefficients of the fitted

${ }^{11}$ McElroy (2008) discusses the relationship of SNR to cycle periodicity, which in the case of $1 / 1600$ is roughly 14 years.

${ }^{12}$ We also ran analyses, not reported here, with other values of the SNR parameter; $1 / 400$ corresponds to a cycle period of ten years. These different choices of the SNR tended to decrease the goodness-of-fit in the subsequent VAR model.

${ }^{13}$ For a step-by-step accounting of how we extract the signal from these data, see Appendix C.

${ }^{14}$ This is consistent with the evidence in similar charts comparing the quit rate and earnings growth in Faberman and Justiniano (2015).

${ }^{15}$ One might consider the broader VARMA class, but the pure VAR is easier to interpret. 
model. Writing $\left\{x_{t}\right\}$ for the vector process for all the variables, the VAR(1) satisfies

$$
x_{t}=\Phi x_{t-1}+\epsilon_{t}
$$

where $\left\{\epsilon_{t}\right\}$ is an independent and identically distributed sequence of random vectors of covariance matrix $\Sigma$. The individual entries of the matrix $\Phi$ are denoted $\Phi_{j k}$. If some entry $\Phi_{j k}$ is significantly different from zero, we say that variable $k$ Granger-causes variable $j$. Of course, this is a feedback system, so it could happen that variable one Granger-causes variable two, and variable two also Granger-causes variable one. To understand the impact of a single shock to this feedback system, it suffices to examine the infinite moving average representation of the process as a function of index (Lütkepohl, 2007). In the case of a $\operatorname{VAR}(1)$, one focuses upon the $j k$ th entry of $\Phi^{t}$ as $t$ increases from $t=1$. Slow decay of such a sequence to zero indicates that the impact of variable $k$ upon variable $j$ is quite persistent.

\subsection{Testing for Variable Significance in a Multivariate Setting}

We raise the following question: given a collection of time series variables for which a VAR(1) model is a correct specification, when is it beneficial to include additional variables? Although it seems this issue would be of empirical importance, there is no treatment or discussion in leading econometric texts treating multivariate time series (e.g., Lütkepohl (2007)). The context of the problem is drawn from the body of this paper: we wish to obtain causal relations among churn, job creation, job destruction, earnings, and employment, but are concerned that the unemployment rate, price level, and GDP also merit inclusion. More generally, economics papers will feature analyses for certain sets of variables, and critics

will wonder why other important or favored variables were omitted. How would the results change with the additional variables?

In regression analysis, such questions are quite natural and have long been solved; Greene (2007, Chapter 5) gives a discussion of specification tests, such as Wald and likelihood ratio. But vector regression can be viewed as a special case of multivariate regression, and the problem becomes more complicated. In univariate regression, omission or inclusion of a covariate has impact only upon a single regression equation, and thus the question can 
be treated with t-statistics or Wald statistics. In multivariate regression, the extension of the same strategy leads to the possibility of a covariate being included in some regression equations, but not in others; the covariate cannot be completely eliminated from the data analysis, unless it has no presence in any of the regression equations.

If an upper triangular or lower triangular block of $\Phi$ is equal to zero, it follows that the corresponding columns indicate a subset of variables that do not Granger-cause those variables corresponding to the rows of zeros. A further interpretation of a zero upper triangular block (and the lower triangular block, by flipping the argument) is that the latter collection of series can be omitted from the model, if interest is focused upon the former batch of series. For example, letting $y_{t}$ denote the vector of churn, job creation, job destruction, earnings, and employment, and with $z_{t}$ denoting the vector of unemployment, price, and gdp, a zero upper triangular block in $\Phi$ would indicate that the latter three control variables can be eliminated from the model.

One way to proceed, is to refit the VAR model with parameter constraints, by constraining any entries of $\Phi$ to be zero if their t-statistic is sufficiently small. Then one could examine the upper triangular blocks of $\Phi$, and see whether any of these blocks are completely zero. The goodness-of-fit test described proceeds by fitting the constrained VAR with a particular upper triangular block set to zero, and checks to see whether the Whittle likelihood (Taniguchi and Kakizawa, 2000) is significantly worsened by this restriction. Another method is to utilize a Wald statistic for all the estimated coefficients in an upper triangular block. The first method requires one to re-estimate the VAR model with insignificant coefficients constrained to be zero; this procedure works quite fast by utilizing the constrained Yule-Walker formulas of McElroy and Findley (2015).

In the context of a $\operatorname{VAR}(1)$ process with matrix $\Phi$, we must retain the $j$ th variable if any of the coefficients in the $j$ th column of $\Phi$ are nonzero. Conversely, if the entire $j$ th column of $\Phi$ is zero, then the $j$ th variable does not Granger-cause any of the other variables, and moreover is itself a white noise process. In such a case, one would be justified in completely removing that variable. More generally, we might not have such a zero column in $\Phi$, but we still wonder whether it is statistically permissible to remove the $j$ th variable. Intuitively, when the removal of such a variable has a salient impact on the coefficients of the refitted model, then we should refrain from its omission. In the following discussion, we use Granger 
causality as the motivating criterion for "benefit of omission," and in particular are interested in cases where the entries of $\Phi$ are invariant under deletion of variables.

\subsubsection{An Example}

It is well-known that even the simple $\operatorname{VAR}(1)$ process allows the analyst to determine causal relations through ancillary variables. We illustrate through a simple (nonstationary) trivariate $\operatorname{VAR}(1)$, with matrix given by

$$
\Phi=\left[\begin{array}{lll}
1 & 0 & a \\
0 & 1 & 0 \\
0 & b & 1
\end{array}\right]
$$

Here $a, b$ are nonzero scalars. Casual (and fallacious) observation indicates that the second series does not cause the first, because $\Phi_{12}=0$. However, in reality the second variable causes the third (through the coefficient $\Phi_{32}=b$ ), which in turn causes the first (through the coefficient $\Phi_{31}=a$ ). This can also be visualized by computing $\Phi^{2}$, which corresponds to the doubly lagged dynamics:

$$
\Phi^{2}=\left[\begin{array}{ccc}
1 & a b & 2 a \\
0 & 1 & 0 \\
0 & 2 b & 1
\end{array}\right]
$$

Evidently, the second series causes the first series, through the ancillary third variable. In a real data analysis with this behavior, omission of the third variable would likely yield estimates of a bivariate $\operatorname{VAR}(1)$ where $\Phi_{12}$ is now nonzero. In fact, if the refitted $\operatorname{VAR}(1)$ still had $\Phi_{12}$ equal to zero, we might conclude that there was no loss - from the perspective of investigating causes of the first variable's dynamics - in omitting the third variable. This illustration can be kept in mind, as we develop the more general problem.

\subsubsection{Restricted VAR Estimation}

Consider a $m$-variate vector time series $\left\{x_{t}\right\}$ that follows a $\operatorname{VAR}(1)$ process, and let the first set of variables be $\left\{y_{t}\right\}$ and the latter set $\left\{z_{t}\right\}$, so that for each $t$ we have $x_{t}^{\prime}=\left[y_{t}^{\prime}, z_{t}^{\prime}\right]$. 
Suppose that our principal interest is in exploring dynamic relationships in $\left\{y_{t}\right\}$, but we are concerned that $\left\{z_{t}\right\}$ might have an impact. It might be the case that modeling $\left\{y_{t}\right\}$ alone with a VAR(1) produces adequate model diagnostics, so that the issue of omission versus retention of the $\left\{z_{t}\right\}$ cannot be resolved simply via model evaluation. The matrix $\Phi$ of the $\operatorname{VAR}(1)$ process $(5)$ is

$$
\Phi=\left[\begin{array}{ll}
\Phi_{y y} & \Phi_{y z} \\
\Phi_{z y} & \Phi_{z z}
\end{array}\right]
$$

where $\Phi$ is partitioned conformably with $x_{t}$, and $\left\{\epsilon_{t}\right\}$ is the white noise error process with variance matrix $\Sigma$. Let $\Gamma_{x x}(h)$ be the autocovariance function of $\left\{x_{t}\right\}$, and let this be partitioned conformably into

$$
\Gamma_{x x}(h)=\operatorname{Cov}\left(x_{t+h}, x_{t}\right)=\left[\begin{array}{cc}
\Gamma_{y y}(h) & \Gamma_{y z}(h) \\
\Gamma_{z y}(h) & \Gamma_{z z}(h)
\end{array}\right]
$$

In what follows, we describe Yule-Walker equations in the process' autocovariances, but by placing a hat upon each autocovariance matrix (interpreted as a sample autocovariance), we obtain the sample version of the all the expressions - the mathematics is the same. Now, our interest is focused upon the submatrix $\Phi_{y y}$. If this matrix is unchanged, once we eliminate $\left\{z_{t}\right\}$ and refit, we conclude that $\left\{z_{t}\right\}$ has no impact on the dynamics of $\left\{y_{t}\right\}$. Let $\Xi_{y y}$ denote the $\operatorname{VAR}(1)$ matrix obtained by fitting to the sub-process $\left\{y_{t}\right\}$ (this could be a mis-specification). Then, we are interested in whether $\Phi_{y y}=\Xi_{y y}$; the following result gives a necessary and sufficient condition.

Proposition 1 Let $\left\{x_{t}\right\}$ be a VAR(1) process given by (5) partitioned into sub-processes $\left\{y_{t}\right\}$ and $\left\{z_{t}\right\}$, with matrix partitioned conformably given by (6). Let $\Xi_{y y}$ be the VAR(1) matrix obtained by fitting to the sub-process $\left\{y_{t}\right\}$. Then $\Phi_{y y}=\Xi_{y y}$ if and only if

$$
\Pi S^{-1} \Gamma_{z y}(0)=0
$$

where $\Pi=\Gamma_{y z}(1)-\Gamma_{y y}(1) \Gamma_{y y}(0)^{-1} \Gamma_{y z}(0)$ and $S=\Gamma_{z z}(0)-\Gamma_{z y}(0) \Gamma_{y y}(0)^{-1} \Gamma_{y z}(0)$.

Proof: See Appendix B for all proofs. 
Condition (7) is satisfied if $\left\{z_{t}\right\}$ and $\left\{y_{t}\right\}$ are not contemporaneously correlated (i.e., $\left.\Gamma_{z y}(0)=0\right)$, or if $\Pi=\operatorname{Cov}\left(y_{t+1}, z_{t} \mid y_{t}\right)$ is zero. It's possible to generalize the result from the $\operatorname{VAR}(1)$ case to other processes. Let $\mathbb{E}[A \mid B]$ denote the minimum mean square linear estimator of a random vector $A$ given a random vector $B$ (which for Gaussian random vectors, is the conditional expectation). Then, we have the following result for covariance stationary processes - generalizing the case of a VAR(1) process.

Proposition 2 Let $\left\{x_{t}\right\}$ be a covariance stationary process partitioned into sub-processes $\left\{y_{t}\right\}$ and $\left\{z_{t}\right\}$. Then

$$
\mathbb{E}\left[y_{t+1} \mid y_{t}, z_{t}\right]=\mathbb{E}\left[y_{t+1} \mid y_{t}\right]+\Pi S^{-1}\left(z_{t}-\mathbb{E}\left[z_{t} \mid y_{t}\right]\right)
$$

where $\Pi=\Gamma_{y z}(1)-\Gamma_{y y}(1) \Gamma_{y y}(0)^{-1} \Gamma_{y z}(0)$. Hence if $\Pi=0, \mathbb{E}\left[y_{t+1} \mid y_{t}, z_{t}\right]=\mathbb{E}\left[y_{t+1} \mid y_{t}\right]$, so that $z_{t}$ offers no additional knowledge over $y_{t}$ for the purposes of forecasting $y_{t+1}$.

Remark 1 The connection to Proposition 1 is as follows. Because

$$
\Phi_{y z}=\left[\Gamma_{y y}(1) \Gamma_{y z}(1)\right]\left[\begin{array}{l}
-\Gamma_{y y}(0)^{-1} \Gamma_{y z}(0) S^{-1} \\
S^{-1}
\end{array}\right]=\Pi S^{-1}
$$

for a $\operatorname{VAR}(1)$ process we obtain

$$
\mathbb{E}\left[y_{t+1} \mid y_{t}, z_{t}\right]=\Phi_{y y} y_{t}+\Pi S^{-1} z_{t}
$$

Also $\mathbb{E}\left[z_{t} \mid y_{t}\right]=\Gamma_{z y}(0) \Gamma_{y y}(0)^{-1} y_{t}$. Hence under the weaker condition (7), we obtain by plugging into (8)

$$
\Phi_{y y} y_{t}+\Pi S^{-1} z_{t}=\Xi_{y y} y_{t}+\Pi S^{-1} z_{t}+0
$$

from which $\Phi_{y y}=\Xi_{y y}$ follows.

As a consequence, we take (8) as the general criterion for omission of $\left\{z_{t}\right\}$, and take $\Pi=0$ as a sufficient condition. Finally, we note that $\Pi=0$ for the $\operatorname{VAR}(1)$ process implies 
that $\left\{z_{t}\right\}$ does not Granger-cause $\left\{y_{t}\right\}$; recall, from Corollary 2.2.1 of Lütkepohl (2007), that $\Phi_{y z}=0$ characterizes Granger non-causality - and hence by (9) $\Pi=0$ also characterizes Granger non-causality. An application of these ideas, is to consider the null hypothesis that $\Pi=0$, with rejections indicating that $\mathbb{E}\left[y_{t+1} \mid y_{t}, z_{t}\right] \neq \mathbb{E}\left[y_{t+1} \mid y_{t}\right]{ }^{16}$ In the case of a $\operatorname{VAR}(1)$, it is sufficient to examine the matrix $\Phi_{y z}$. In terms of a statistical test, one could utilize a Wald test on all the coefficients in $\Phi_{y z}$. In particular, let $\phi_{y z}=\operatorname{vec} \Phi_{y z}$ and $\phi=\operatorname{vec} \Phi_{x x}$, and note that the Yule-Walker estimates $\widehat{\phi}$ of $\phi$ obey a central limit theorem, given in (3.4.25) of Lütkepohl (2007). For matrices of appropriate dimension $E_{1}=\left[\begin{array}{ll}1 & 0\end{array}\right]$ and $E_{2}^{\prime}=\left[\begin{array}{ll}0 & 1\end{array}\right]$, we can write $\phi_{z y}=\left[E_{2}^{\prime} \otimes E_{1}\right] \phi$, and it then follows that the asymptotic variance is given by

$$
V=\left[\begin{array}{lllll}
0 & 0 & 0 & 1 & 0
\end{array}\right]\left[\Gamma_{x x}(0)^{-1} \otimes \Sigma\right]\left[\begin{array}{lllll}
0 & 0 & 0 & 1 & 0
\end{array}\right]^{\prime} .
$$

This matrix $V$ can be consistently estimated by plugging in $\widehat{\Gamma}_{x x}(0)$ and $\widehat{\Sigma}$, with the resulting estimate denoted by $\widehat{V}$. Then the Wald statistic is $\widehat{\phi}_{y z}^{\prime} \widehat{V}^{-1} \widehat{\phi}_{y z}$, and has an asymptotic $\chi^{2}$ distribution with degrees of freedom given by the number of entries in $\Phi_{y z}$.

In classical regression, omission of covariates can be tested with the Wald test, or alternatively by a likelihood ratio comparison. We next outline this approach, as an alternative to the Wald test of $\Pi=0$. Recall that Yule-Walker fitting of a VAR model is justified by the Whittle likelihood (McElroy and Findley 2015), and the fitted value of this Whittle likelihood is equal to

$$
\mathcal{W}(\widehat{\theta})=T \log \operatorname{det} \widehat{\Sigma}
$$

where $T$ is sample size and $\widehat{\Sigma}$ is the Yule-Walker estimate of $\Sigma$. Here $\theta$ stands for the full vector of parameters, including both $\operatorname{vec} \Phi$ and the diagonal and sub-diagonal entries of $\Sigma$. If we impose parameter restrictions and refit, the Whittle likelihood will increase and the difference in fitted values is asymptotically $\chi^{2}$ with degrees of freedom equal to the number of restrictions; see Taniguchi and Kakizawa (2000, Section 3.1).

Note that the t-statistic for each coefficient of $\Phi$ considered individually can mislead one into constraining too many entries to zero, because of the multiple-testing fallacy. Our recommended procedure is to sequentially constrain various entries of $\Phi$ to be zero and conduct

${ }^{16}$ Note that the two conditional expectations can still be equal if $z_{t}=\mathbb{E}\left[z_{t} \mid y_{t}\right]$; but this is a freakish case, indicating perfect knowledge of $z_{t}$ from $y_{t}$. 
a test that these are all zero, by comparing the Whittle likelihoods for the constrained model and the fully unconstrained model. We begin with the least extreme t-statistic, replacing the corresponding coefficient with zero, and compute the Whittle likelihood ratio test; if there is no rejection of the null, proceed to the second least extreme t-statistic and replace the corresponding coefficient with zero, etc. At each iteration, we compare to the fully unconstrained model, and proceed until there is a significant difference in the fitted Whittle likelihoods (say, at a $5 \%$ level). The result is a goodness-of-fit test of $\Pi=0$. Either we can directly impose the $\Phi_{y z}=0$ constraint and check the resulting $\chi^{2}$ test, or we can use the above sequential procedure to find the overall best constrained model fit and check whether $\Phi_{y z}$ is completely zero.

We have here proposed the criterion (8) for checking specification robustness with respect to omitted variables, i.e., whether our results are sensitive to omission. We argue for reducing this concept to the mathematical criterion of $\Pi=0$, which, in the case of a $\operatorname{VAR}(1)$, is equivalent to $\Phi_{y z}=0$; this can be tested with a Wald statistic or a goodness-of-fit (Whittle likelihood comparison) test.

In what follows, we will refer to the version of the model in which we set parameters equal to zero via a Yule-Walker test as our "restricted model," while conventional VAR estimation is called our "unrestricted model." We employ custom R code to estimate the parameters via an extension of the Yule-Walker method that allows for parameter restrictions, see McElroy and Findley (2015).

\section{Results}

\subsection{Quarterly Data and LEHD Earnings}

\subsubsection{Baseline Findings}

The basic relationships between our variables of interest are shown in Table 1, which shows the VAR parameter estimates for churn, job creation, job destruction, LEHD earnings, and employment. The first thing to note is that the relationship has a dominant diagonal: all five relationships are positive and statistically significant, and are all less than one. This 
indicates that movements for each variable tend to predict movements in that variable, and the fact that they are less than one is a rough indication of stationarity. ${ }^{17}$ We can see that some relationships are statistically significant, while others are not. For example, increases in churn predict (Granger-cause) job creation, LEHD earnings, and employment ratio. Increases in the employment-to-population ratio Granger-cause decreases in churn and job creation and increases in job destruction.

The restricted model can increase the precision of estimates by setting insignificant relationships to be equal to zero. Estimates are reported in Table 2, and there are a few things to note here. First, not all the remaining relationships are statistically significant: there is an imprecise relationship between job destruction and LEHD earnings, the exclusion of which significantly reduces the fit of the model. While the fit is imprecise, the sign of the relationship is positive, and, indeed, in other specifications this relationship turns out to be positive and significant. All other relationships included in the restricted version of the model were statistically significant in the unrestricted case. Furthermore, the precision of the remaining estimates increases, which is quite natural given that the number of parameters to be estimated is fewer in this case.

We also present impulse-response charts to show how shocks to any of the variables of interest affect other variables in the system. These are shown in Figure 3. These take into consideration how the measures respond to the shock in the one via the direct effects of the parameter estimates and the secondary effects caused by other variables. For example, the restricted model did not include any direct effect of employment on LEHD earnings. However, because a shock to employment Granger-causes decreases in churn and increases job destruction, each of which has its own effect on LEHD earnings, there can be an effect on earnings. These impulse-response plots show what the overall impact of all primary and secondary relationships is. In the case of the overall effect of an increase in employment, there is initially zero effect (the first period's effects are determined only by primary relationships). But there is a negative impact on earnings over the five years (twenty quarters), reaching $-0.03 \log$ points per quarter about two years after the increase, all of which is due to secondary channels. On the other hand, an increase in churn leads to a substantial increase in earnings. A change in churn from $0 \%$ to $100 \%$ has an initial period effect of 0.478 as

${ }^{17}$ Stationarity is enforced by Yule-Walker estimation, but is credible given the behavior of the cycles. 
shown in Table 2 and increases to about 0.7 after a year.

There is one additional aspect to note about the baseline model. It is shown that an increase in employment Granger-causes decreases in job creation and churn, and increases job destruction. This may be surprising, but is a logical consequence of the fundamental relationships between the data elements. Increased employment in one period predicts increased employment in the next, but by far less - only about $70 \%$ of the employment growth in the previous period. Job creation and job destruction must sum to the change in employment, by definition. Therefore, if the level of the change in employment is less than that of the previous period, either job creation must be lower, job destruction must be lower, or both. Indeed, the estimates suggest that both factors are at play. Churn does not have a similar deterministic relationship with employment as do job creation and destruction, but appears to move with employment and so is lower when employment growth is only $70 \%$ what it was in the previous quarter.

There is more to learn from Figure 3. The only labor reallocation rate that affects the employment-to-population ratio as shown in Table 2 is churn. Because (aside from churn itself) only employment Granger-causes churn, and likewise only churn Granger-causes employment (apart from employment itself), innovations to these measures affect each other. Furthermore, churn and employment both Granger-cause job creation, and employment Granger-causes job destruction, so shocks to churn and employment Granger-cause changes to job creation and job destruction. By contrast, LEHD earnings do not Granger-cause changes to any other series, and so a one log point shock to LEHD earnings affects only itself and dissipates over time. Job destruction affects LEHD earnings, but because LEHD earnings do not Granger-cause changes to other series, the effect of an increase in job destruction begins at its initial level of 0.523 and dissipates to $0.523^{t}$ by quarter $t$.

\subsubsection{Inclusion of Additional Variables}

We estimated an additional eight variants of the VAR shown by including additional variables as controls. The effects of our independent variables of interest (churn, job creation, and job destruction) on our dependent variables of interest (earnings and employment) are 
summarized in Table 3. ${ }^{18}$ Churn is found to Granger-cause increases in LEHD earnings and employment in nearly all specifications. These exceptions can be due to correlations between the different measures. That is, churn is not found to Granger-cause increases in employment when we include the unemployment rate alone, and the unemployment rate and employment move together because movements between employment, unemployment, and non-participation in the CPS must sum to the total population. Churn is not found to Granger-cause increases in earnings when GDP alone is included, and churn and GDP move together very strongly. ${ }^{19}$ But note that when we include the price level, GDP, and the unemployment rate, churn is found to Granger-cause increases in employment and earnings that are similar in magnitude to the estimates from the small model - compare columns (1) and (2) to column (6).

Increases in churn inducing increases in earnings and employment is consistent with churn signaling increased labor demand. When there is a lot of hiring and separations that do not move workers into and out of the labor market, firms are competing with each other for the portion of the workforce that is most willing to work and the earnings increases are consistent with better matches for the workers or more bargaining power for workers. Increases in employment also suggest that employers are pulling in more marginally attached workers who may enter, because firms work harder to find appropriate jobs for them, or because they are induced to join the workforce because of the higher wages being offered by firms.

Job creation and job destruction do not influence LEHD earnings or employment to the same degree that churn does. Job destruction is found to Granger-cause increases in LEHD earnings, and this relationship is robust across specifications. Increases in job destruction leading to increased earnings is consistent with job destruction having a "cleansing" effect, i.e., the most marginal jobs are destroyed. Job creation does not appear to be related to either increases in LEHD earnings or employment.

Because the relationships between our independent and dependent variables of interest are somewhat sensitive to the additional variables that we include in the VAR, we present

${ }^{18}$ These are selected point estimates from a number of models as reported in the previous tables as well as Appendix D. For an impulse-response chart of the most general model, see Appendix E.

${ }^{19}$ When we include GDP alone in the VAR, it has a strong positive impact on earnings, suggesting that GDP innovations account for most of the increases in LEHD earnings that are accounted for by churn when GDP is omitted. 
the results of VAR models in which all variables are included in both the unrestricted and restricted models in Table 4 . Increased churn is found to increase employment at the same time as it Granger-causes lower unemployment. Churn is also found to have a relationship with the price level, although it leads to lower prices in the unrestricted model and higher prices in the restricted model. If churn increases prices, then it may do so via increases in the nominal earnings rate. Churn is not found to Granger-cause increases in GDP.

Once again, job destruction has more of a relationship with the variables included in the VAR than job creation. Job destruction Granger-causes increases in the unemployment rate and decreases in GDP. This makes sense: when workers lose their jobs they quickly move into unemployment, and if fewer workers are employed in the production of goods and services, then output measured by GDP should decline. Although it is plausible that job creation should have the opposite effect (decreasing unemployment and increasing GDP) there is no statistically significant relationship found. Neither job creation nor job destruction are found to Granger-cause changes in the price level.

\subsection{Quarterly Data and Alternative Measures of Earnings}

It is well-known that measures of employment from different data sources move together more strongly than measures of worker earnings; see Champagne and Kurmann (2013). Therefore, we fitted some alternative VAR models in which we replaced LEHD earnings with CES average earnings for production and nonsupervisory workers, which is the longest continuously available earnings measure for the U.S. We also substituted the CPS median earnings series published by the BLS for LEHD earnings. Selected parameter estimates are included as Table $5 .^{20}$

The inclusion of these alternative earnings measures affects which labor reallocation measures Granger-cause increases in earnings. First, note that none of the labor reallocation measures seem to Granger-cause changes in the CES earnings series. This may be because the CES average earnings level is not as tied to aggregate employment reallocation as the economy-wide average earnings level is. Or, it may be because the CES earnings series is only for workers who are paid by the hour and excludes salaried workers. If earnings results

${ }^{20}$ For the full set of parameter estimates from all specifications, see Appendix E. 
are concentrated among more highly paid workers, then this too provides a mechanism which would be consistent with labor reallocation having little effect on the CES earnings series.

The CPS median earnings results are more consistent with the LEHD earnings results. Here, we find an effect of job destruction on CPS median weekly earnings for full-time workers that is similar in magnitude to the LEHD earnings results. Again, job destruction Granger-causes increases in earnings. However, churn is not found to Granger-cause changes in the CPS median weekly earnings series. Again, this may be due to the measures under consideration. If LEHD earnings increases are concentrated among more highly paid workers, then effects may not be found at the median although they may be so found among the higher end. If the positive Granger-causal effect of job destruction on earnings is truly due to cleansing, then it is plausible that this has an effect on the median earnings, which are closer to the lower tail affected by cleansing than high earners, who also have more dispersion.

\section{Conclusion}

We estimated a number of VAR models to assess the relationship between labor reallocation, employment, and earnings. Our estimates describe what economic variables Granger-cause each other: that is, the changes to one series predict changes that occur soon after to other series. Of particular interest was whether labor reallocation measures Granger-cause employment or earnings growth. We distinguish between three types of labor reallocation: job creation, job destruction, and churn.

We find a robust positive effect of labor market churn on employment: when labor market churn increases in one quarter, it predicts that employment will grow in the next. We find more mixed results on the relationship between employment reallocation rates and earnings, and earnings results vary by the series employed. Job destruction and churn both Grangercause increases in LEHD earnings, but have little relationship with two other earnings series: the CES earnings series, as well as the CPS median weekly earnings of full-time workers. Of these two, the CPS median weekly earnings series has more of a relationship with the other variables that we analyze, and job destruction is found to Granger-cause increases in this series.

This evidence suggests that there is a more straightforward relationship between labor 
market reallocation rates and employment than there is between reallocation and earnings. While many mechanisms for a relationship between labor market reallocation and earnings growth exist, only some of our specifications suggest that these mechanisms have predictive power. Further inquiry into these relationships will help us better understand why labor market churn, employment, and earnings are procyclical and thus are correlated over longer intervals.

\section{References}

[1] Abowd, John, and Lars Vilhuber. 2011. "National estimates of gross employment and job flows from the Quarterly Workforce Indicators with demographic and industry detail" Journal of Econometrics 161(1): 82-99.

[2] Abraham, Katharine, James Spletzer, and Jay Stewart. 1998. "Divergent Trends in Alternative Wage Series." In: Labor Statistics Measurement Issues, ed. John Haltiwanger, Marilyn Manser, and Robert Topel. Chicago, IL: University of Chicago Press: 293-325.

[3] Acemoglu, Daron, David Autor, David Dorn, Gordon H. Hanson, and Brendan Price. 2015. Import Competition and the Great U.S. Employment Sag of the 2000s. NBER Working Paper \# 20395, http://www.nber.org/papers/w20395.pdf. Forthcoming, Journal of Labor Economics.

[4] Barlevy, Gadi. 2002. "The Sullying Effect of Recessions." Review of Economic Studies 69(1): 65-96.

[5] Barth, Erling, Alex Bryson, James Davis, and Richard Freeman. 2014. "It's Where You Work: Increases in Earnings Dispersion Across Establishments and Individuals in the U.S." NBER Working Paper \#20447.

[6] Burgess, Simon, Julia Lane, and David Stevens. 2000. "Job Flows, Worker Flows, and Churning." Journal of Labor Economics 18(3): 473-502.

[7] Cahuc, Pierre, Fabien Postel-Vinay, and Jean-Marc Robin. 2006. "Wage Bargaining with On-the-Job Search: Theory and Evidence." Econometrica 74(2): 323-364. 
[8] Cairo, Isabel, Henry Hyatt, and Nellie Zhao. 2015. "The U.S. Job Ladder in the New Millennium." Unpublished draft, U.S. Census Bureau.

[9] Champagne, Julien, and André Kurmann. 2013. "Reconciling the divergence in aggregate U.S. wage series." Unpublished draft, Bank of Canada.

[10] Davis, Steven, R. Jason Faberman, and John Haltiwanger. 2006. "The Flow Approach to Labor Markets: New Data Sources and Micro-Macro Links." Journal of Economic Perspectives 20(3): 3-26.

[11] Davis, Steven, and John Haltiwanger. 2014. "Labor Market Fluidity and Economic Performance." NBER Working Paper \# 20479, http://www.nber.org/papers/w20479. pdf. Forthcoming, Proceedings of the Jackson Hole Symposium, Federal Reserve Bank of Kansas.

[12] Economic Report of the President. 2015. "Achievements and Challenges in the U.S. Labor Market." https://www. whitehouse.gov/sites/default/files/docs/2015_erp_ chapter_3.pdf.

[13] Faberman, R. Jason, and Alejandro Justiniano. 2015. "Job Switching and Wage Growth." Chicago Fed Letter No. 337.

[14] Gómez, Victor. 2016. Multivariate Time Series With Linear State Space Structure. New York: Springer.

[15] Granger, Clive. 1969. "Investigating Causal Relations by Econometric Models and Cross-spectral Methods." Econometrica 37(3): 424-438.

[16] Greene, William H. 2007. Econometric Analysis. Prentice Hall, 7th Edition.

[17] Hahn, Joyce K., Henry R. Hyatt, and Hubert P. Janicki. 2016. "Job Ladders and Growth in Earnings, Hours, and Wages: 1994-2014." Unpublished draft, U.S. Census Brueau.

[18] Haltiwanger, John, Henry Hyatt, and Erika McEntarfer. 2015. "Cyclical Reallocation of Workers Across Employers by Firm Size and Firm Wage." NBER Working Paper \#21235. 
[19] Hodrick, Robert, and Edward Prescott. 1997. Postwar U.S. business cycles: an empirical investigation. Journal of Money, Credit, and Banking 29(1): 1-16.

[20] Hyatt, Henry R., and James R. Spletzer. 2013. "The Recent Decline in Employment Dynamics." IZA Journal of Labor Economics, 2(5): 1-21. http://www.izajole.com/ content/pdf/2193-8997-2-5.pdf.

[21] Hyatt, Henry R., and James R. Spletzer. 2016. "The Recent Decline of Single Quarter Jobs." Forthcoming, Labour Economics.

[22] Kahn, Lisa, and Erika McEntarfer. 2014. "Employment Cyclicality and Firm Quality." NBER Working Paper \#20698.

[23] Lazear, Edward P. and James R. Spletzer. 2012. "Hiring, Churn, and the Business Cycle." American Economic Review Papers and Proceedings, 102(3): 575-579. http: //www . jstor . org/stable/pdf/23245596.

[24] Lütkepohl, Helmut. 2007. New Introduction to Multiple Time Series Analysis. New York: Springer.

[25] McElroy, Tucker. 2008. "Exact Formulas for the Hodrick-Prescott Filter." Econometrics Journal 11(1): 1-9.

[26] McElroy, Tucker, and David Findley. 2015. "Fitting Constrained Vector Autoregression Models." In J. Beran, Y. Feng, and H. Hebbel (Eds.), Empirical Economic and Financial Research - Theory, Methods, and Practice. New York: Springer.

[27] Taniguchi, Masanobu, and Yoshihide Kakizawa. 2000. Asymptotic Theory of Statistical Inference for Time Series. New York: Springer.

[28] Topel, Robert, and Michael Ward. 1992. "Job Mobility and the Careers of Young Men." Quarterly Journal of Economics 107(2): 439-479.

[29] U.S. Census Bureau (2016). X-13ARIMA-SEATS Reference Manual, U.S. Census Bureau, Washington D.C. USA. 
[30] Yellen, Janet. 2014. "Labor Market Dynamics and Monetary Policy." http://www . federalreserve.gov/newsevents/speech/yellen20140822a.pdf. 


\section{A Data Details}

\section{A.1 Source Data}

\section{A.1.1 LEHD Data on Labor Reallocation, Employment, and Earnings}

LEHD data on job creation, job destruction, hires, and separations, employment, and earnings come from the national-level LEHD Quarterly Workforce Indicators using the method developed by Abowd and Vilhuber (2011). These data can be downloaded from http://ledextract.ces.census.gov/, and they are the "00 National (50 States + DC)" series.

Employment counts come from the Quarterly Workforce Indicators. Following Abowd and Vilhuber (2011), employment is the average of "beginning of quarter" and "end of quarter employment," that is, the average of consecutive quarter jobs in which the reference quarter is the subsequent and previous quarter, respectively.

LEHD earnings data is the total earnings of workers who are employed for three consecutive quarters, and the earnings reference the middle quarter. Earnings data are converted to real terms using the price level.

\section{A.1.2 The Unemployment Rate}

Data on unemployment comes from the Bureau of Labor Statistics. This is a tabulation of CPS microdata on responses concerning employment and unemployment. The quarterly not seasonally adjusted unemployment rate was downloaded from http://www.bls.gov/data/ \#unemployment.

\section{A.1.3 Price Level Data}

Data on the price level comes from the Bureau of Labor Statistics, specifically the not seasonally adjusted Consumer Price Index for all items, U.S. city average, series CUUS0000SA0. It can be downloaded from http://www.bls.gov/cpi/data.htm. 


\section{A.1.4 GDP}

Data on GDP come from the Bureau of Economic Analysis, see http://www.bea.gov/ national/index.htm\#gdp. The GDP series is converted into real terms using the price level.

\section{A.1.5 Additional Earnings Data Sources}

Average weekly earnings data comes from the Current Employment Statistics (CES). These data are for production and nonsupervisory workers, that is, those who are paid by the hour. Data are available monthly, and we average the three months of each quarter to create a quarterly series. The data were downloaded from https://research.stlouisfed.org/ fred2/series/CEU0500000030.

Median weekly earnings data comes from the Current Population Survey (CPS). It is the median weekly earnings among full-time workers. The Bureau of Labor Statistics publishes these data on a monthly and quarterly basis, and we use the quarterly series. All earnings series are converted to real terms using the price level. We use the not seasonally adjusted version, which was downloaded from http://www.bls.gov/data/\#wages.

\section{A.2 Adjustment Details}

All data were adjusted for outliers, calendar effects, and seasonality using X-13ARIMASEATS. The four labor series all had significant trading day effects, and for jc and jd a log transformation was automatically recommended (these variables are kept in their original scale for the subsequent analysis). For emp, three additive outlier and two level shift effects were identified; the additive outlier effects were removed from the seasonal adjustment (but the level shift effects were retained, belonging to the trend). The CES earnings series were already seasonally adjusted, but were adjusted for trading day and additive outliers; the LEHD and CPS earnings series were each processed, requiring a log transformation each, and a trading day effect in the case of LEHD. No outliers were detected. Finally, for the control variables, the unemployment rate required a log transform and trading day, but had no outliers; the price level series had no trading day, but required a log transform - 
also a level shift was detected, but this was not removed from the data. As for GDP, no modification was made (X-13ARIMA-SEATS finds a level shift, but this was not removed).

\section{B Proofs}

Proof of Proposition 1. From McElroy and Findley (2015), we have $\Xi_{y y}=\Gamma_{y y}(1) \Gamma_{y y}(0)^{-1}$. Likewise $\Phi_{x x}=\Gamma_{x x}(1) \Gamma_{x x}(0)^{-1}$, and using the Schur decomposition with $S=\Gamma_{z z}(0)-$ $\Gamma_{z y}(0) \Gamma_{y y}(0)^{-1} \Gamma_{y z}(0)$ and $I_{m}$ the $m \times m$ identity matrix, we obtain

$$
\begin{aligned}
\Gamma_{x x}(0)^{-1} & =\left[\begin{array}{cc}
\Gamma_{y y}(0)^{-1}\left(I_{m}+\Gamma_{y z}(0) S^{-1} \Gamma_{z y}(0) \Gamma_{y y}(0)^{-1}\right) & -\Gamma_{y y}(0)^{-1} \Gamma_{y z}(0) S^{-1} \\
-S^{-1} \Gamma_{z y}(0) \Gamma_{y y}(0)^{-1} & S^{-1}
\end{array}\right] \\
\Phi_{y y} & =\left[\Gamma_{y y}(1) \Gamma_{y z}(1)\right]\left[\begin{array}{l}
\Gamma_{y y}(0)^{-1}\left(I_{m}+\Gamma_{y z}(0) S^{-1} \Gamma_{z y}(0) \Gamma_{y y}(0)^{-1}\right) \\
-S^{-1} \Gamma_{z y}(0) \Gamma_{y y}(0)^{-1}
\end{array}\right] \\
& =\Gamma_{y y}(1) \Gamma_{y y}(0)^{-1}-\left(\Gamma_{y z}(1)-\Gamma_{y y}(1) \Gamma_{y y}(0)^{-1} \Gamma_{y z}(0)\right) S^{-1} \Gamma_{z y}(0) \Gamma_{y y}(0)^{-1} .
\end{aligned}
$$

Thus,

$$
\Phi_{y y}=\Xi_{y y}-\Pi S^{-1} \Gamma_{z y}(0) \Gamma_{y y}(0)^{-1} .
$$

Proof of Proposition 2. The formula (8) follows from standard projection theory (Gómez, 2015), recognizing that $S=\operatorname{Var}\left(z_{t} \mid y_{t}\right)$. 


\section{Seasonally Adjusted Data}
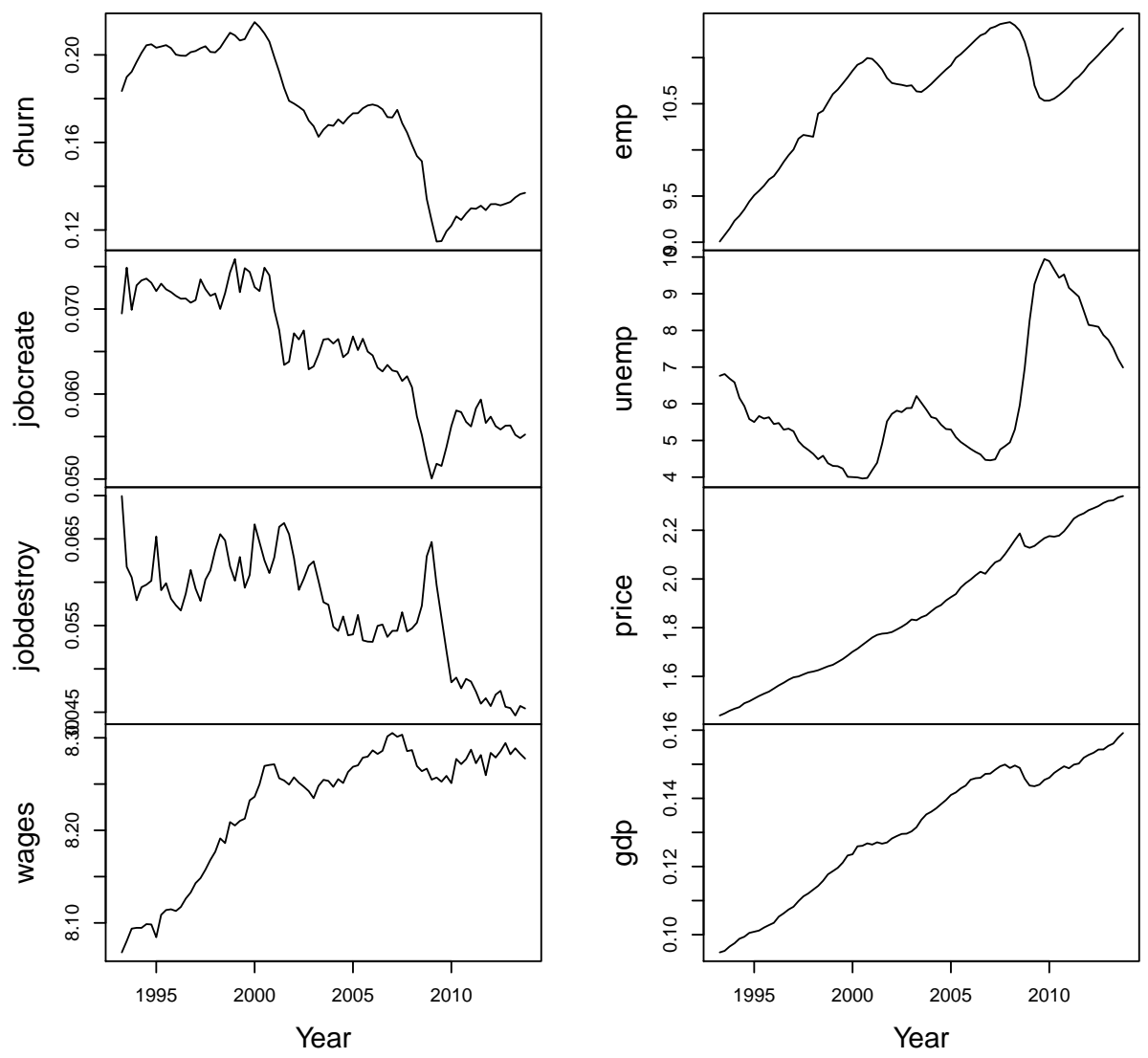

Figure 1: Seasonal adjustments of Labor data, 1993.Q2 through 2013.Q4 (i.e., seasonal adjustment with additive outliers removed). Employment is in tens of millions, price is in hundreds, and GDP is in hundreds of thousands. 


\section{HP Cycles}
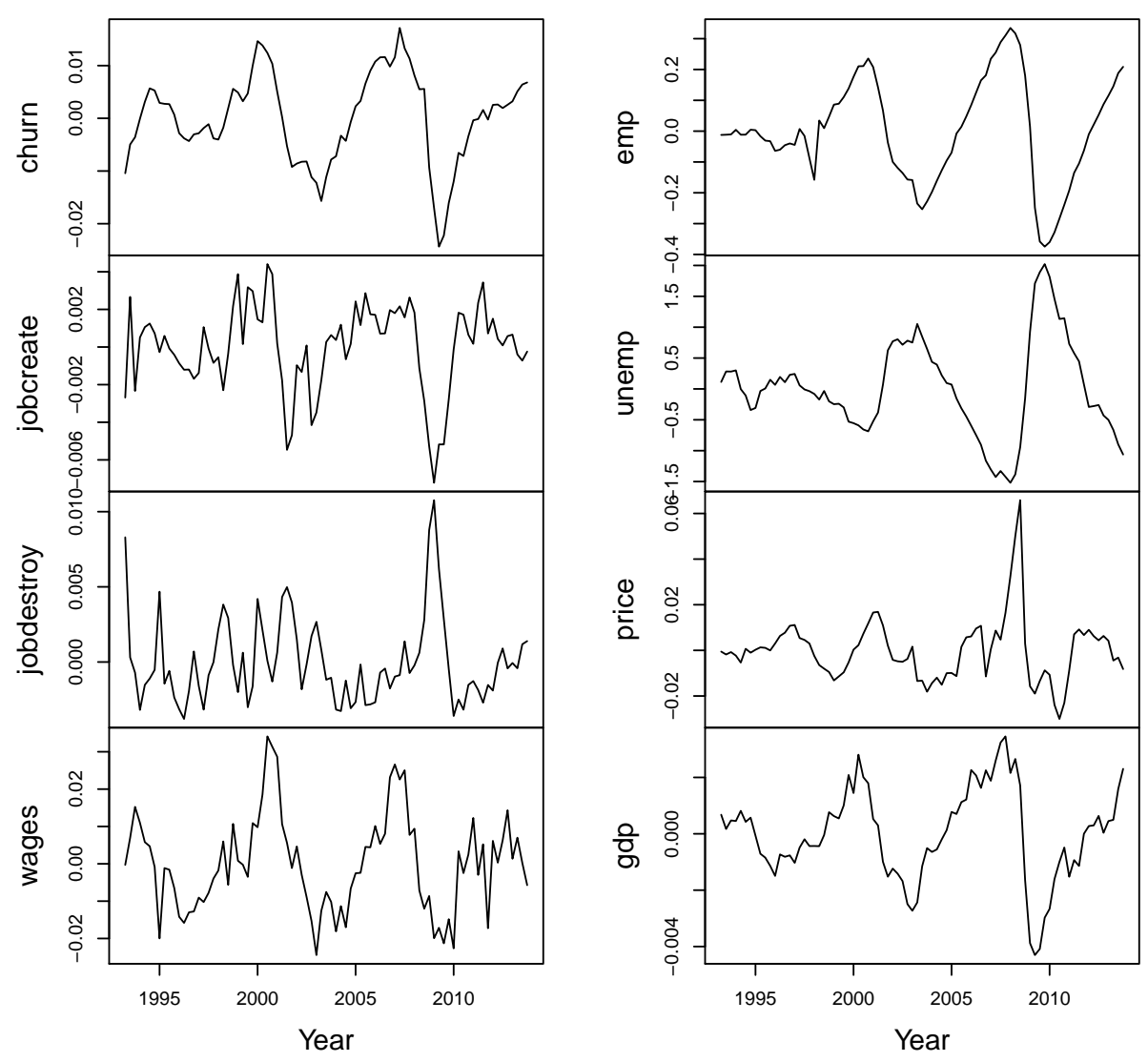

Figure 2: Cycles of Labor data, 1993.Q2 through 2013.Q4. The cycles are computed by applying the HP high-pass filter with signal-to-noise ratio equal to 1/1600 to the adjusted data. 

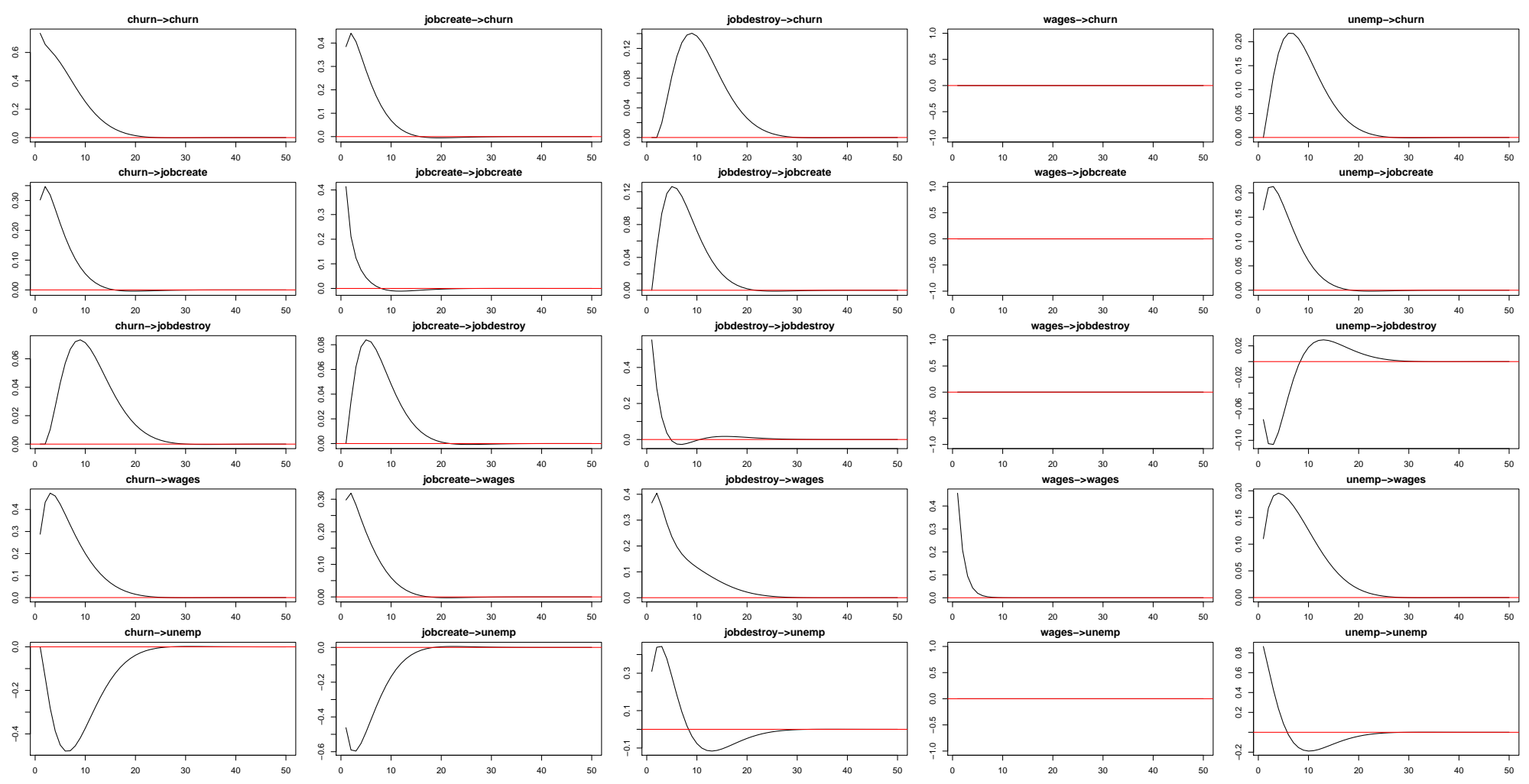

Figure 3: Impulse response functions for cycle components of Labor data, 1993.Q2 through 2013.Q4. 
Table 1: Small Model, No Parameter Restrictions

\begin{tabular}{rlllll}
\hline \hline & \multicolumn{5}{c}{ Effect of: } \\
\cline { 2 - 6 } Effect on: & Churn & JC & JD & Earnings & Emp \\
\hline Churn & $0.966^{* * *}$ & 0.289 & -0.119 & 0.042 & $-0.011^{* *}$ \\
& $(0.114)$ & $(0.310)$ & $(0.194)$ & $(0.039)$ & $(0.005)$ \\
JC & $0.204^{* * *}$ & $0.360^{* *}$ & 0.083 & 0.017 & $-0.010^{* * *}$ \\
& $(0.057)$ & $(0.153)$ & $(0.096)$ & $(0.019)$ & $(0.002)$ \\
JD & -0.079 & -0.146 & $0.370^{* * *}$ & -0.001 & $0.009^{* * *}$ \\
& $(0.078)$ & $(0.210)$ & $(0.132)$ & $(0.026)$ & $(0.003)$ \\
Earnings & $0.639^{* *}$ & $1.259^{* *}$ & 1.266 & $0.510^{* * *}$ & -0.019 \\
& $(0.292)$ & $(0.789)$ & $(0.495)$ & $(0.099)$ & $(0.012)$ \\
Emp & $5.102^{* * *}$ & 4.458 & -2.225 & 0.616 & $0.693^{* * *}$ \\
& $(1.504)$ & $(4.069)$ & $(2.552)$ & $(0.510)$ & $(0.062)$ \\
\hline
\end{tabular}

Notes: Standard errors in parentheses. ${ }^{*},{ }^{* *}$, and ${ }^{* * *}$ indicate statistical significance at the $10 \%, 5 \%$, and $1 \%$ level, respectively. Variables are Churn, Job Creation (JC), Job Destruction (JD), LEHD Earnings, and Employment (Emp).

Table 2: Small Model, with Parameter Restrictions

\begin{tabular}{rlllll}
\hline \hline & \multicolumn{5}{c}{ Effect of: } \\
\cline { 2 - 6 } Effect on: & Churn & JC & JD & Earnings & Emp \\
\hline Churn & $1.076^{* * *}$ & $0^{\dagger}$ & $0^{\dagger}$ & $0^{\dagger}$ & $-0.012^{* * *}$ \\
& $(0.061)$ & $(0)$ & $(0)$ & $(0)$ & $(0.003)$ \\
JC & $0.186^{* * *}$ & $0.240^{* * *}$ & $0^{\dagger}$ & $0^{\dagger}$ & $-0.007^{* * *}$ \\
& $(0.039)$ & $(0.091)$ & $(0)$ & $(0)$ & $(0.002)$ \\
JD & $0^{\dagger}$ & $0^{\dagger}$ & $0.523^{* * *}$ & $0^{\dagger}$ & $0.004^{* * *}$ \\
& $(0)$ & $(0)$ & $(0.071)$ & $(0)$ & $(0.001)$ \\
Earnings & $0.478^{* *}$ & $0^{\dagger}$ & 0.377 & $0.497^{* * *}$ & $0^{\dagger}$ \\
& $(0.148)$ & $(0)$ & $(0.318)$ & $(0.090)$ & $(0)$ \\
Emp & $7.739^{* * *}$ & $0^{\dagger}$ & $0^{\dagger}$ & $0^{\dagger}$ & $0.629^{* * *}$ \\
& $(0.883)$ & $(0)$ & $(0)$ & $(0)$ & $(0.045)$ \\
\hline
\end{tabular}

Notes: Standard errors in parentheses. ${ }^{*},{ }^{* *}$, and ${ }^{* * *}$ indicate statistical significance at the $10 \%, 5 \%$, and $1 \%$ level, respectively. $\dagger$ indicates that the relationship is constrained to be equal to zero. Variables are Churn, Job Creation (JC), Job Destruction (JD), LEHD Earnings, and Employment (Emp). 
Table 3: VAR Specifications, LEHD Earnings Series

\begin{tabular}{|c|c|c|c|c|c|c|}
\hline Effect on: & (1) & (2) & (3) & (4) & (5) & (6) \\
\hline & \multicolumn{6}{|c|}{ Effect of Churn } \\
\hline Earnings & $\begin{array}{l}0.639^{* *} \\
(0.292)\end{array}$ & $\begin{array}{l}0.478^{* * *} \\
(0.148)\end{array}$ & $\begin{array}{l}0.294^{*} \\
(0.165)\end{array}$ & $\begin{array}{l}0.412^{* * *} \\
(0.146)\end{array}$ & $\begin{array}{l}0^{\dagger} \\
(0)\end{array}$ & $\begin{array}{l}0.511^{*} \\
(0.280)\end{array}$ \\
\hline Emp & $\begin{array}{l}5.102^{* * *} \\
(1.504)\end{array}$ & $\begin{array}{l}7.739^{* * *} \\
(0.883)\end{array}$ & $\begin{array}{l}0^{\dagger} \\
(0)\end{array}$ & $\begin{array}{l}7.426^{* * *} \\
(0.830)\end{array}$ & $\begin{array}{l}4.516^{* * *} \\
(1.292)\end{array}$ & $\begin{array}{l}3.291^{* * *} \\
(1.165)\end{array}$ \\
\hline & \multicolumn{6}{|c|}{ Effect of Job Creation } \\
\hline Earnings & $\begin{array}{l}1.259 \\
(0.789)\end{array}$ & $\begin{array}{l}0^{\dagger} \\
(0)\end{array}$ & $\begin{array}{l}1.265 \\
(0.701)\end{array}$ & $\begin{array}{l}0^{\dagger} \\
(0)\end{array}$ & $\begin{array}{l}0^{\dagger} \\
(0)\end{array}$ & $\begin{array}{l}0^{\dagger} \\
(0)\end{array}$ \\
\hline Emp & $\begin{array}{l}4.458 \\
(4.069)\end{array}$ & $\begin{array}{l}0^{\dagger} \\
(0)\end{array}$ & $\begin{array}{l}0^{\dagger} \\
(0)\end{array}$ & $\begin{array}{l}0^{\dagger} \\
(0)\end{array}$ & $\begin{array}{l}0^{\dagger} \\
(0)\end{array}$ & $\begin{array}{l}0^{\dagger} \\
(0)\end{array}$ \\
\hline & \multicolumn{6}{|c|}{ Effect of Job Destruction } \\
\hline Earnings & $\begin{array}{l}1.266^{* *} \\
(0.495)\end{array}$ & $\begin{array}{l}0.377 \\
(0.318)\end{array}$ & $\begin{array}{l}0.973^{* *} \\
(0.425)\end{array}$ & $\begin{array}{l}0.198 \\
(0.320)\end{array}$ & $\begin{array}{l}0.733^{* *} \\
(0.367)\end{array}$ & $\begin{array}{l}0.890^{* * *} \\
(0.341)\end{array}$ \\
\hline Emp & $\begin{array}{l}-2.225^{* *} \\
(2.552)\end{array}$ & $\begin{array}{l}0^{\dagger} \\
(0)\end{array}$ & $\begin{array}{l}0^{\dagger} \\
(0)\end{array}$ & $\begin{array}{l}0^{\dagger} \\
(0)\end{array}$ & $\begin{array}{l}0^{\dagger} \\
(0)\end{array}$ & $\begin{array}{l}0^{\dagger} \\
(0)\end{array}$ \\
\hline Controls: & & & & & & \\
\hline UR & & & $\mathrm{X}$ & & & $\mathrm{X}$ \\
\hline Price & & & & $\mathrm{X}$ & & $\mathrm{X}$ \\
\hline GDP & & & & & $\mathrm{X}$ & $\mathrm{X}$ \\
\hline Restricted & No & Yes & Yes & Yes & Yes & Yes \\
\hline
\end{tabular}

Notes: Standard errors in parentheses. ${ }^{*}, * *$, and ${ }^{* * *}$ indicate statistical significance at the $10 \%, 5 \%$, and $1 \%$ level, respectively. $\dagger$ indicates that the relationship is constrained to be equal to zero. The full set of parameter estimates for column (1) are presented in Table 1, the full set of parameter estimates for column (2) are presented in Table 2, the full set of parameter estimates for column (3) are presented in Appendix Table D4, the full set of parameter estimates for column (4) are presented in Appendix Table D6, the full set of parameter estimates for column (5) are presented in Appendix Table D8, and the full set of parameter estimates for column (6) are presented in Appendix Table D2. 
Table 4: Effect of Labor Reallocation on All Variables, LEHD Earnings Series

\begin{tabular}{|c|c|c|c|c|c|c|}
\hline \multirow[b]{2}{*}{ Effect on: } & \multicolumn{2}{|c|}{ Effect of Churn } & \multicolumn{2}{|c|}{$\begin{array}{c}\text { Effect of } \\
\text { Job Creation }\end{array}$} & \multicolumn{2}{|c|}{$\begin{array}{c}\text { Effect of } \\
\text { Job Destruction }\end{array}$} \\
\hline & $(1)$ & $(2)$ & $(3)$ & (4) & $(5)$ & $(6)$ \\
\hline Churn & $\begin{array}{l}0.793^{* * *} \\
(0.118)\end{array}$ & $\begin{array}{l}0.840^{* * *} \\
(0.077)\end{array}$ & $\begin{array}{l}-0.109 \\
(0.296)\end{array}$ & $\begin{array}{l}0^{\dagger} \\
(0)\end{array}$ & $\begin{array}{l}-0.236 \\
(0.183)\end{array}$ & $\begin{array}{l}-0.114 \\
(0.112)\end{array}$ \\
\hline $\mathrm{JC}$ & $\begin{array}{l}0.171^{* * *} \\
(0.059)\end{array}$ & $\begin{array}{l}0.187^{* * *} \\
(0.036)\end{array}$ & $\begin{array}{l}0.147 \\
(0.148)\end{array}$ & $\begin{array}{l}0^{\dagger} \\
(0)\end{array}$ & $\begin{array}{l}0.004 \\
(0.092)\end{array}$ & $\begin{array}{l}0^{\dagger} \\
(0)\end{array}$ \\
\hline JD & $\begin{array}{l}-0.057 \\
(0.087)\end{array}$ & $\begin{array}{l}0^{\dagger} \\
(0)\end{array}$ & $\begin{array}{l}0.011 \\
(0.217)\end{array}$ & $\begin{array}{l}0^{\dagger} \\
(0)\end{array}$ & $\begin{array}{l}0.439^{* * *} \\
(0.134)\end{array}$ & $\begin{array}{l}0.492^{* * *} \\
(0.069)\end{array}$ \\
\hline Earnings & $\begin{array}{l}0.560^{*} \\
(0.315)\end{array}$ & $\begin{array}{l}0.511^{*} \\
(0.280)\end{array}$ & $\begin{array}{l}0.499 \\
(0.789)\end{array}$ & $\begin{array}{l}0^{\dagger} \\
(0)\end{array}$ & $\begin{array}{l}1.081^{* *} \\
(0.488)\end{array}$ & $\begin{array}{l}0.890^{* * *} \\
(0.341)\end{array}$ \\
\hline Emp & $\begin{array}{l}1.951 \\
(1.570)\end{array}$ & $\begin{array}{l}3.291^{* * *} \\
(1.165)\end{array}$ & $\begin{array}{l}4.378 \\
(3.924)\end{array}$ & $\begin{array}{l}0^{\dagger} \\
(0)\end{array}$ & $\begin{array}{l}-0.305 \\
(2.428)\end{array}$ & $\begin{array}{l}0^{\dagger} \\
(0)\end{array}$ \\
\hline UR & $\begin{array}{r}-10.767 \\
(7.481)\end{array}$ & $\begin{array}{l}-15.213^{* * *} \\
(5.042)\end{array}$ & $\begin{array}{l}-13.969 \\
(18.697)\end{array}$ & $\begin{array}{l}0^{\dagger} \\
(0)\end{array}$ & $\begin{array}{l}28.294^{* *} \\
(11.568)\end{array}$ & $\begin{array}{l}28.122^{* * *} \\
(7.062)\end{array}$ \\
\hline Price & $\begin{array}{l}-0.614^{*} \\
(0.349)\end{array}$ & $\begin{array}{l}0.377^{* * *} \\
(0.120)\end{array}$ & $\begin{array}{l}0.812 \\
(0.872)\end{array}$ & $\begin{array}{l}0^{\dagger} \\
(0)\end{array}$ & $\begin{array}{l}-0.602 \\
(0.539)\end{array}$ & $\begin{array}{l}0^{\dagger} \\
(0)\end{array}$ \\
\hline GDP & $\begin{array}{l}0.024 \\
(0.027)\end{array}$ & $\begin{array}{l}0^{\dagger} \\
(0)\end{array}$ & $\begin{array}{l}0.230 \\
(0.068)\end{array}$ & $\begin{array}{l}0^{\dagger} \\
(0)\end{array}$ & $\begin{array}{l}-0.062 \\
(0.042)\end{array}$ & $\begin{array}{l}-0.088^{* * *} \\
(0.024)\end{array}$ \\
\hline Restricted & No & Yes & No & Yes & No & Yes \\
\hline
\end{tabular}

Notes: Standard errors in parentheses. ${ }^{*},{ }^{* *}$, and ${ }^{* * *}$ indicate statistical significance at the $10 \%, 5 \%$, and $1 \%$ level, respectively. $\dagger$ indicates that the relationship is constrained to be equal to zero. The full set of parameter estimates for columns (1), (3), and (5) are presented in Appendix Table D1, and the full set of parameter estimates for columns (2), (4), and (6) are presented in Appendix Table D2. 
Table 5: VAR Specifications, with Alternative Earnings Measures

\begin{tabular}{|c|c|c|c|c|}
\hline Effect on: & (1) & $(2)$ & $(3)$ & (4) \\
\hline CES Average Earnings & $\begin{array}{l}0.112 \\
(0.183)\end{array}$ & $\begin{array}{l}\text { Effect o. } \\
0.0^{\dagger} \\
(0)\end{array}$ & f Churn & \\
\hline CPS Median Earnings & & & $\begin{array}{l}-0.301 \\
(0.229)\end{array}$ & $\begin{array}{l}0^{\dagger} \\
(0)\end{array}$ \\
\hline Emp & $\begin{array}{l}5.395^{* * *} \\
(1.492)\end{array}$ & $\begin{array}{l}7.812^{* * *} \\
(0.880)\end{array}$ & $\begin{array}{l}5.210^{* * *} \\
(1.519)\end{array}$ & $\begin{array}{l}7.808^{* * *} \\
(0.883)\end{array}$ \\
\hline CES Average Earnings & $\begin{array}{l}-0.387 \\
(0.525)\end{array}$ & $\begin{array}{l}\text { effect of } J \\
0^{\dagger} \\
(0)\end{array}$ & b Creatic & \\
\hline CPS Median Earnings & & & $\begin{array}{l}0.399 \\
(0.613)\end{array}$ & $\begin{array}{l}0^{\dagger} \\
(0)\end{array}$ \\
\hline Emp & $\begin{array}{l}4.258 \\
(4.272)\end{array}$ & $\begin{array}{l}0^{\dagger} \\
(0)\end{array}$ & $\begin{array}{l}6.625 \\
(4.063)\end{array}$ & $\begin{array}{l}0^{\dagger} \\
(0)\end{array}$ \\
\hline CES Average Earnings & $\begin{array}{r}E \\
-0.068 \\
(0.347)\end{array}$ & $\begin{array}{l}\text { fect of Job } \\
0^{\dagger} \\
(0)\end{array}$ & Destruct & \\
\hline CPS Median Earnings & & & $\begin{array}{l}0.757^{*} \\
(0.405)\end{array}$ & $\begin{array}{l}0.816^{* *} \\
(0.249)\end{array}$ \\
\hline Emp & $\begin{array}{l}-2.830 \\
(2.821)\end{array}$ & $\begin{array}{l}0^{\dagger} \\
(0)\end{array}$ & $\begin{array}{l}-0.997 \\
(2.686)\end{array}$ & $\begin{array}{l}0^{\dagger} \\
(0)\end{array}$ \\
\hline Restricted & No & Yes & No & Yes \\
\hline
\end{tabular}

Notes: Standard errors in parentheses. ${ }^{*},{ }^{* *}$, and $* * *$ indicate statistical significance at the $10 \%, 5 \%$, and $1 \%$ level, respectively. $\dagger$ indicates that the relationship is constrained to be equal to zero. The full set of parameter estimates for column (1) are presented in Appendix Table E3, the full set of parameter estimates for column (2) are presented in Appendix Table E4, the full set of parameter estimates for column (3) are presented in Appendix Table E13, and the full set of parameter estimates for column (4) are presented in Appendix Table E14. 


\section{Signal Extraction in Detail (Web Appendix)}

The not seasonally adjusted employment reallocation rate series are plotted in Figure C1. Hire and separation rates appear very strongly correlated with each other, and in the analysis in the body of the paper we difference hires from job creation and focus on churn, job creation, and job destruction. There is evidence of substantial seasonality in all the series.

Our three dependent variables of interest - earnings (log of nominal LEHD earnings, called wage in the figure), employment (emp), and unemployment (unemp) - are plotted in Figure C2. There is substantial seasonality in the earnings series, and apparent seasonality in the other two series as well.

The price level and GDP show substantial increases through the 1990s and 2000s with noticeable downturns in the recession years of 2008 and 2009, and are plotted in Figure C3.

The HP trends are plotted in C4. Labor reallocation rate trends are level in the 1990s and then have a declining trend through the 2000s. LEHD earnings increases in the 1990s but then is flat during the 2000s, as is employment. Trend unemployment appears to surge in the wake of the labor market downturn associated with the 2007-2009 recession. The price level and GDP grow persistently, although trend growth in GDP is lower from 2006 to 2011. 


\section{Labor Series}

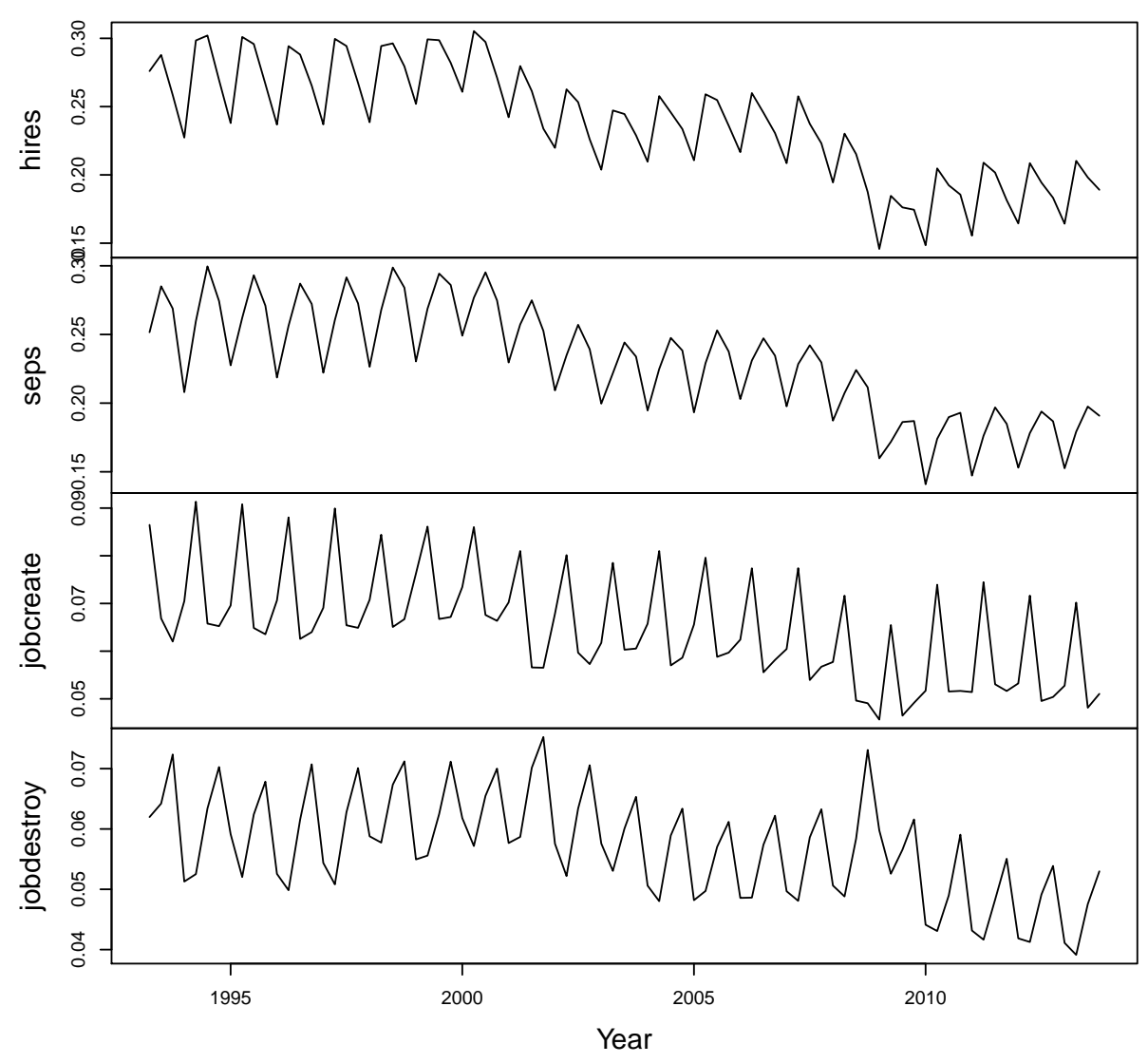

Figure C1: Labor data, 1993.Q2 through 2013.Q4, not seasonally adjusted. Source: U.S. Census Bureau. 


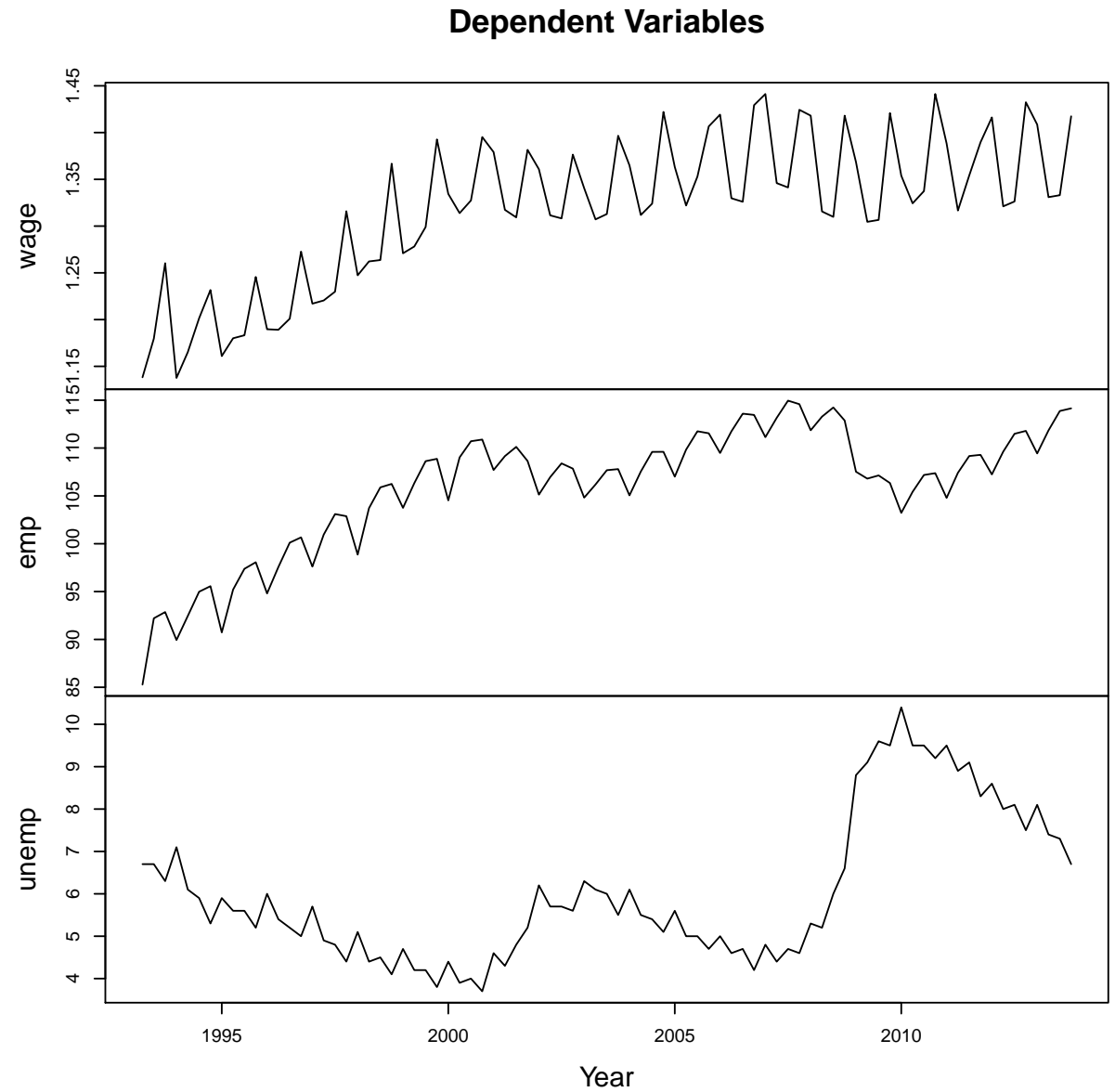

Figure C2: Labor data, 1993.Q2 through 2013.Q4, not seasonally adjusted. Source: U.S. Census Bureau (earnings and employment), Bureau of Labor Statistics (unemployment). 


\section{Auxiliary Variables}

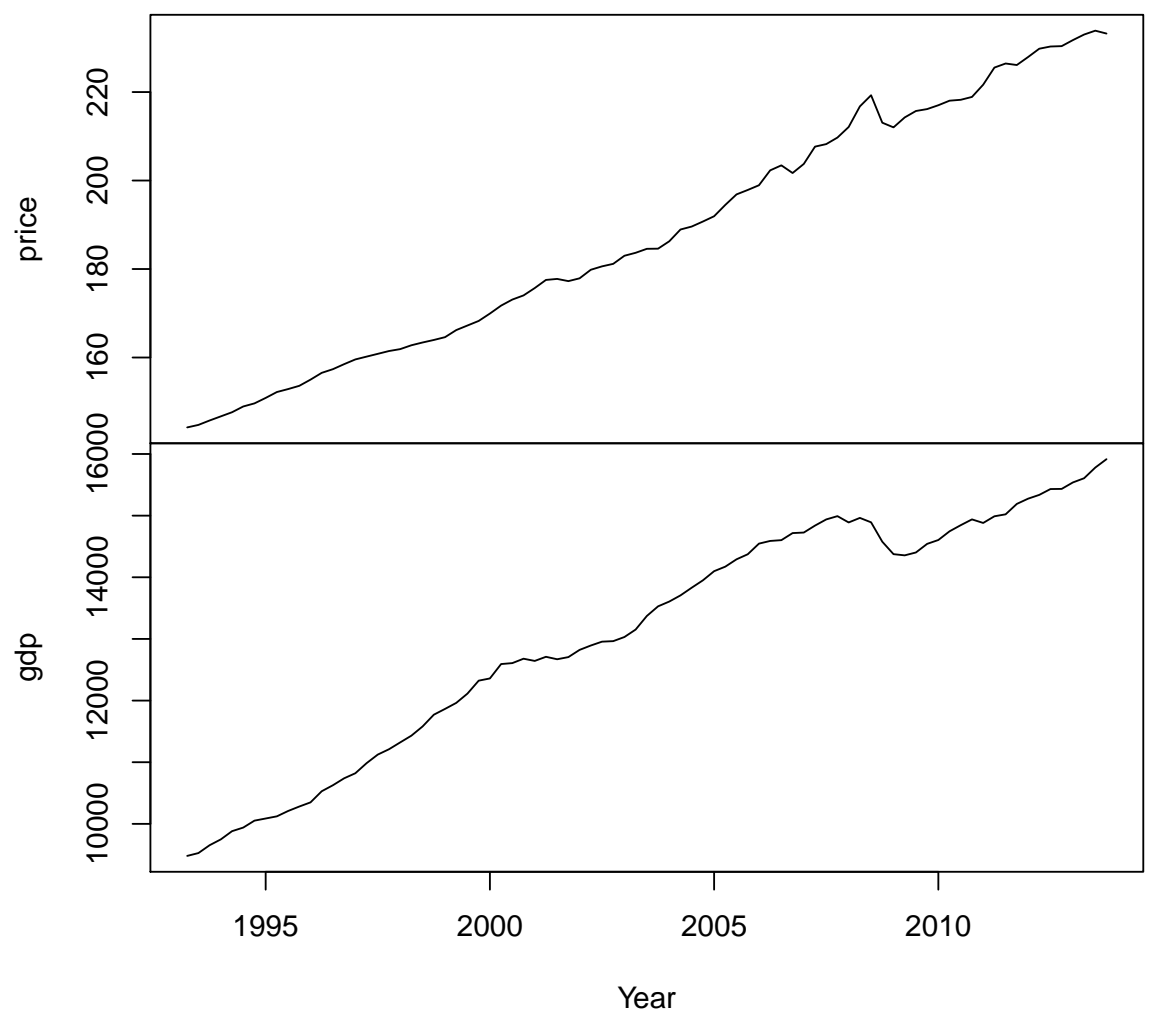

Figure C3: Price and GDP series, 1993.Q2 through 2013.Q4. Source: Bureau of Labor Statistics (price level) and Bureau of Economic Analysis (GDP). 


\section{HP Trends}
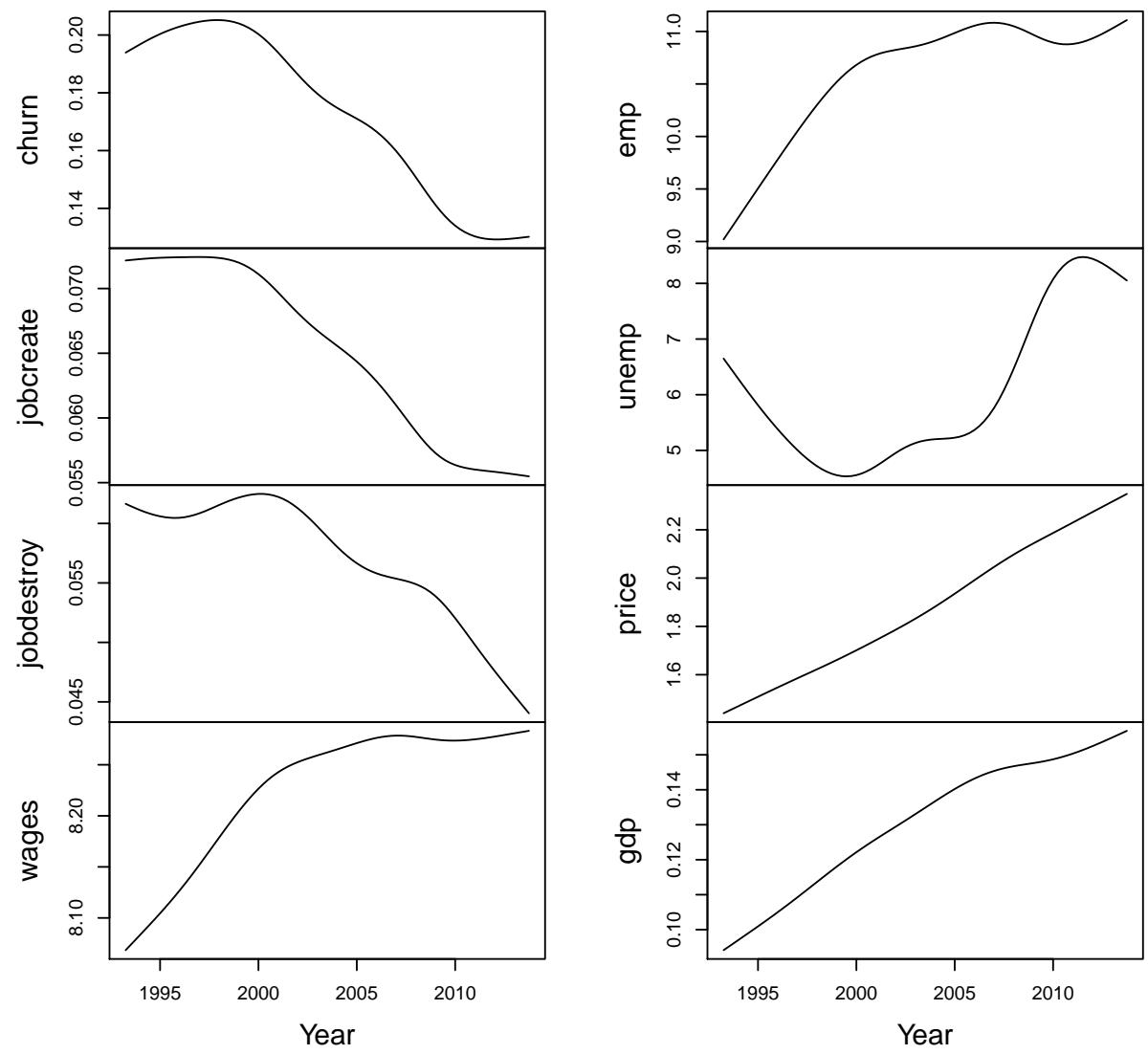

Figure C4: Trends of Labor data, 1993.Q2 through 2013.Q4. The trends are computed by applying the HP low-pass filter with signal-to-noise ratio equal to 1/1600 to the adjusted data. 


\section{Detailed Tables of VAR Results with LEHD Earn- ings (For Web Appendix)}


Table D1: Full Model, No Parameter Restrictions, Using LEHD Earnings

\begin{tabular}{rllllllll}
\hline \hline & \multicolumn{7}{c}{ Effect of: } \\
\cline { 2 - 9 } Effect on: & Churn & JC & JD & Earnings & Emp & UR & Price & GDP \\
\hline Churn & $0.793^{* * *}$ & -0.109 & -0.236 & 0.032 & $-0.014^{* *}$ & -0.001 & $-0.093^{* * *}$ & $1.436^{* *}$ \\
& $(0.118)$ & $(0.296)$ & $(0.183)$ & $(0.037)$ & $(0.007)$ & $(0.002)$ & $(0.031)$ & $(0.558)$ \\
JC & $0.171^{* * *}$ & 0.147 & 0.004 & -0.001 & $-0.006^{* *}$ & 0.001 & $-0.044^{* * *}$ & $0.840^{* * *}$ \\
& $(0.059)$ & $(0.148)$ & $(0.092)$ & $(0.019)$ & $(0.003)$ & $(0.001)$ & $(0.016)$ & $(0.280)$ \\
JD & -0.057 & 0.011 & $0.439^{* * *}$ & 0.012 & 0.006 & -0.001 & $0.041^{*}$ & -0.479 \\
& $(0.087)$ & $(0.217)$ & $(0.134)$ & $(0.027)$ & $(0.005)$ & $(0.001)$ & $(0.023)$ & $(0.41)$ \\
Earnings & $0.560^{*}$ & 0.499 & $1.081^{* *}$ & $0.427^{* * *}$ & -0.001 & $0.009^{* *}$ & -0.066 & $4.517^{* * *}$ \\
& $(0.315)$ & $(0.789)$ & $(0.488)$ & $(0.1)$ & $(0.019)$ & $(0.004)$ & $(0.083)$ & $(1.489)$ \\
Emp & 1.951 & 4.378 & -0.305 & $1.182^{* *}$ & $0.400^{* * *}$ & $-0.065^{* * *}$ & 0.508 & 10.43 \\
& $(1.57)$ & $(3.924)$ & $(2.428)$ & $(0.495)$ & $(0.092)$ & $(0.022)$ & $(0.411)$ & $(7.407)$ \\
UR & -10.767 & -13.969 & $28.294^{* *}$ & $-4.202^{*}$ & $1.169^{* * *}$ & $0.971^{* * *}$ & 1.264 & -27.168 \\
& $(7.481)$ & $(18.697)$ & $(11.568)$ & $(2.359)$ & $(0.44)$ & $(0.105)$ & $(1.957)$ & $(35.299)$ \\
Price & $-0.614^{*}$ & 0.812 & -0.602 & 0.135 & 0.007 & -0.006 & $0.631^{* * *}$ & 0.506 \\
& $(0.349)$ & $(0.872)$ & $(0.539)$ & $(0.110)$ & $(0.021)$ & $(0.005)$ & $(0.091)$ & $(1.646)$ \\
GDP & 0.024 & 0.023 & -0.062 & 0.012 & -0.002 & $-0.001^{* * *}$ & $-0.017^{* *}$ & $0.611^{* * *}$ \\
& $(0.027)$ & $(0.068)$ & $(0.042)$ & $(0.009)$ & $(0.002)$ & $(0.000)$ & $(0.007)$ & $(0.129)$ \\
\hline
\end{tabular}

Notes: Standard errors in parentheses. * **, and *** indicate statistical significance at the $10 \%, 5 \%$, and $1 \%$ level, respectively. $\dagger$ indicates that the relationship is constrained to be equal to zero. Variables are Churn, Job Creation (JC), Job Destruction (JD), LEHD Earnings, Employment (Emp), Unemployment Rate (UR), Price Level, and GDP. 
Table D2: Full Model, with Parameter Restrictions, Using LEHD Earnings

\begin{tabular}{rllllllll}
\hline \hline & \multicolumn{7}{c}{ Effect of: } \\
\cline { 2 - 3 } & Churn & JC & JD & Earnings & Emp & UR & Price & GDP \\
\hline Churn & $0.84^{* * *}$ & $0^{\dagger}$ & -0.114 & $0^{\dagger}$ & -0.006 & $0^{\dagger}$ & $-0.095^{* * *}$ & $1.192^{* * *}$ \\
& $(0.077)$ & $(0)$ & $(0.112)$ & $(0)$ & $(0.004)$ & $(0)$ & $(0.023)$ & $(0.381)$ \\
JC & $0.187^{* * *}$ & $0^{\dagger}$ & $0^{\dagger}$ & $0^{\dagger}$ & $-0.004^{* *}$ & 0.001 & $-0.049^{* * *}$ & $0.774^{* * *}$ \\
& $(0.036)$ & $(0)$ & $(0)$ & $(0)$ & $(0.002)$ & $(0.001)$ & $(0.013)$ & $(0.197)$ \\
JD & $0^{\dagger}$ & $0^{\dagger}$ & $0.492^{* * *}$ & $0^{\dagger}$ & $0^{\dagger}$ & $0^{\dagger}$ & $0.055^{* * *}$ & $0^{\dagger}$ \\
& $(0)$ & $(0)$ & $(0.069)$ & $(0)$ & $(0)$ & $(0)$ & $(0.016)$ & $(0)$ \\
Earnings & $0.511^{*}$ & $0^{\dagger}$ & $0.890^{* * *}$ & $0.472^{* * *}$ & $0^{\dagger}$ & $0.010^{* * *}$ & $0^{\dagger}$ & $4.789^{* * *}$ \\
& $(0.280)$ & $(0)$ & $(0.341)$ & $(0.086)$ & $(0)$ & $(0.003)$ & $(0)$ & $(1.381)$ \\
Emp & $3.291^{* * *}$ & $0^{\dagger}$ & $0^{\dagger}$ & $1.031^{* *}$ & 0.44 & $-0.058^{* * *}$ & $0^{\dagger}$ & $9.266^{*}$ \\
& $(1.165)$ & $(0)$ & $(0)$ & $(0.408)$ & $(0.065)$ & $(0.018)$ & $(0)$ & $(5.563)$ \\
UR & $-15.213^{* * *}$ & $0^{\dagger}$ & $28.122^{* * *}$ & $-4.835^{* * *}$ & $1.081^{* * *}$ & $0.963^{* * *}$ & $0^{\dagger}$ & $0^{\dagger}$ \\
& $(5.042)$ & $(0)$ & $(7.062)$ & $(1.852)$ & $(0.318)$ & $(0.076)$ & $(0)$ & $(0)$ \\
Price & $0.377^{* * *}$ & $0^{\dagger}$ & $0^{\dagger}$ & $0^{\dagger}$ & $0^{\dagger}$ & $0^{\dagger}$ & $0.654^{* * *}$ & $0^{\dagger}$ \\
& $(0.12)$ & $(0)$ & $(0)$ & $(0)$ & $(0)$ & $(0)$ & $(0.074)$ & $(0)$ \\
GDP & $0^{\dagger}$ & $0^{\dagger}$ & $-0.088^{* * *}$ & $0.013^{* *}$ & $0^{\dagger}$ & $-0.001^{* * *}$ & $-0.019^{* * *}$ & $0.61^{* * *}$ \\
& $(0)$ & $(0)$ & $(0.024)$ & $(0.006)$ & $(0)$ & $(0)$ & $(0.005)$ & $(0.094)$ \\
\hline
\end{tabular}

Notes: Standard errors in parentheses. ${ }^{*},{ }^{* *}$, and $* * *$ indicate statistical significance at the $10 \%, 5 \%$, and $1 \%$ level, respectively. $\dagger$ indicates that the relationship is constrained to be equal to zero. Variables are Churn, Job Creation (JC), Job Destruction (JD), LEHD Earnings, Employment (Emp), Unemployment Rate (UR), Price Level, and GDP. 
Table D3: Small Model Plus the Unemployment Rate, No Parameter Restrictions, Using LEHD Earnings

\begin{tabular}{rllllll}
\hline \hline & \multicolumn{6}{c}{ Effect of: } \\
\cline { 2 - 7 } Effect on: & Churn & JC & JD & Earnings & Emp & UR \\
\hline Churn & $0.863^{* * *}$ & 0.295 & -0.076 & 0.063 & $-0.021^{* * *}$ & -0.003 \\
& $(0.126)$ & $(0.304)$ & $(0.192)$ & $(0.040)$ & $(0.007)$ & $(0.002)$ \\
JC & $0.212^{* * *}$ & $0.360^{* *}$ & 0.080 & 0.015 & $-0.009^{* *}$ & 0.000 \\
& $(0.064)$ & $(0.153)$ & $(0.097)$ & $(0.020)$ & $(0.004)$ & $(0.001)$ \\
JD & -0.081 & -0.145 & $0.370^{* * *}$ & -0.001 & $0.009^{*}$ & 0 \\
& $(0.087)$ & $(0.210)$ & $(0.133)$ & $(0.028)$ & $(0.005)$ & $(0.001)$ \\
Earnings & $0.780^{* *}$ & 1.250 & $1.206^{* *}$ & $0.480^{* * *}$ & -0.006 & 0.004 \\
& $(0.325)$ & $(0.784)$ & $(0.496)$ & $(0.103)$ & $(0.019)$ & $(0.004)$ \\
Emp & 2.459 & 4.613 & -1.107 & $1.173^{* *}$ & $0.438^{* * *}$ & $-0.077^{* * *}$ \\
& $(1.559)$ & $(3.763)$ & $(2.378)$ & $(0.494)$ & $(0.089)$ & $(0.021)$ \\
UR & $-12.095^{*}$ & -20.465 & $26.105^{* *}$ & $-4.696^{* *}$ & $1.263^{* * *}$ & $1.003^{* * *}$ \\
& $(7.326)$ & $(17.681)$ & $(11.176)$ & $(2.321)$ & $(0.418)$ & $(0.097)$ \\
\hline
\end{tabular}

Notes: Standard errors in parentheses. ${ }^{*},{ }^{* *}$, and ${ }^{* * *}$ indicate statistical significance at the $10 \%, 5 \%$, and $1 \%$ level, respectively. $\dagger$ indicates that the relationship is constrained to be equal to zero. Variables are Churn, Job Creation (JC), Job Destruction (JD), LEHD Earnings, Employment (Emp), and Unemployment Rate (UR). 
Table D4: Small Model Plus the Unemployment Rate, with Parameter Restrictions, Using LEHD Earnings

\begin{tabular}{rllllll}
\hline \hline & \multicolumn{6}{c}{ Effect of: } \\
\cline { 2 - 7 } Effect on: & Churn & JC & JD & Earnings & Emp & UR \\
\hline Churn & $0.779^{* * *}$ & $0^{\dagger}$ & $0^{\dagger}$ & $0.079^{* * *}$ & $-0.026^{* * *}$ & $-0.005^{* * *}$ \\
& $(0.072)$ & $(0)$ & $(0)$ & $(0.030)$ & $(0.005)$ & $(0.001)$ \\
JC & $0.170^{* * *}$ & $0.266^{* * *}$ & $0^{\dagger}$ & $0^{\dagger}$ & $-0.007^{* * *}$ & $0^{\dagger}$ \\
& $(0.039)$ & $(0.091)$ & $(0)$ & $(0)$ & $(0.002)$ & $(0)$ \\
JD & $0^{\dagger}$ & $0^{\dagger}$ & $0.515^{* * *}$ & $0^{\dagger}$ & $0.004^{* * *}$ & $0^{\dagger}$ \\
& $(0)$ & $(0)$ & $(0.071)$ & $(0)$ & $(0.001)$ & $(0)$ \\
Earnings & $0.294^{*}$ & $1.265^{*}$ & $0.973^{* *}$ & $0.478^{* * *}$ & $0^{\dagger}$ & $0^{\dagger}$ \\
& $(0.165)$ & $(0.701)$ & $(0.425)$ & $(0.093)$ & $(0)$ & $(0)$ \\
Emp & $0^{\dagger}$ & $0^{\dagger}$ & $0^{\dagger}$ & $2.028^{* * *}$ & $0.298^{* * *}$ & $-0.127^{* * *}$ \\
& $(0)$ & $(0)$ & $(0)$ & $(0.429)$ & $(0.076)$ & $(0.016)$ \\
UR & -5.277 & $0^{\dagger}$ & $25.464^{* * *}$ & $-6.821^{* * *}$ & $1.626^{* * *}$ & $1.149^{* * *}$ \\
& $(4.720)$ & $(0)$ & $(6.954)$ & $(2.006)$ & $(0.368)$ & $(0.083)$ \\
\hline
\end{tabular}

Notes: Standard errors in parentheses. ${ }^{*},{ }^{* *}$, and ${ }^{* * *}$ indicate statistical significance at the $10 \%, 5 \%$, and $1 \%$ level, respectively. $\dagger$ indicates that the relationship is constrained to be equal to zero. Variables are Churn, Job Creation (JC), Job Destruction (JD), LEHD Earnings, Employment (Emp), and Unemployment Rate (UR). 
Table D5: Small Model Plus the Price Level, No Parameter Restrictions, Using LEHD Earnings

\begin{tabular}{rllllll}
\hline \hline & \multicolumn{6}{c}{ Effect of: } \\
\cline { 2 - 7 } Effect on: & Churn & JC & JD & Earnings & Emp & Price \\
\hline Churn & $0.965^{* * *}$ & 0.072 & -0.277 & 0.023 & -0.004 & $-0.096^{* * *}$ \\
& $(0.109)$ & $(0.304)$ & $(0.193)$ & $(0.038)$ & $(0.005)$ & $(0.033)$ \\
JC & $0.204^{* * *}$ & $0.257^{*}$ & 0.009 & 0.008 & $-0.006^{* *}$ & $-0.045^{* * *}$ \\
& $(0.054)$ & $(0.151)$ & $(0.096)$ & $(0.019)$ & $(0.003)$ & $(0.016)$ \\
JD & -0.079 & -0.052 & $0.438^{* * *}$ & 0.007 & 0.006 & $0.041^{*}$ \\
& $(0.076)$ & $(0.212)$ & $(0.134)$ & $(0.026)$ & $(0.004)$ & $(0.023)$ \\
Earnings & $0.639^{* *}$ & 1.095 & $1.147^{* *}$ & $0.495^{* * *}$ & -0.014 & -0.072 \\
& $(0.290)$ & $(0.81)$ & $(0.513)$ & $(0.100)$ & $(0.014)$ & $(0.087)$ \\
Emp & $5.105^{* * *}$ & 5.57 & -1.417 & 0.713 & 0.657 & 0.489 \\
& $(1.494)$ & $(4.168)$ & $(2.641)$ & $(0.514)$ & $(0.070)$ & $(0.450)$ \\
Price & -0.368 & 0.864 & -0.695 & 0.092 & $0.028^{* *}$ & $0.630^{* * *}$ \\
& $(0.307)$ & $(0.856)$ & $(0.542)$ & $(0.106)$ & $(0.014)$ & $(0.092)$ \\
\hline
\end{tabular}

Notes: Standard errors in parentheses. ${ }^{*}, * *$, and ${ }^{* * *}$ indicate statistical significance at the $10 \%, 5 \%$, and $1 \%$ level, respectively. $\dagger$ indicates that the relationship is constrained to be equal to zero. Variables are Churn, Job Creation (JC), Job Destruction (JD), LEHD Earnings, Employment (Emp), and Price Level. 
Table D6: Small Model Plus the Price Level, with parameter restrictions, Using LEHD Earnings

\begin{tabular}{rllllll}
\hline \hline & \multicolumn{7}{c}{ Effect of: } \\
\cline { 2 - 7 } Effect on: & Churn & JC & JD & Earnings & Emp & Price \\
\hline Churn & $0.939^{* * *}$ & $0^{\dagger}$ & $-0.208^{* *}$ & $0^{\dagger}$ & $0^{\dagger}$ & $-0.107^{* * *}$ \\
& $(0.041)$ & $(0)$ & $(0.095)$ & $(0)$ & $(0)$ & $(0.022)$ \\
JC & $0.164^{* * *}$ & $0.274^{* * *}$ & $0^{\dagger}$ & $0^{\dagger}$ & $-0.004^{* *}$ & $-0.045^{* * *}$ \\
& $(0.037)$ & $(0.092)$ & $(0)$ & $(0)$ & $(0.002)$ & $(0.014)$ \\
JD & $0^{\dagger}$ & $0^{\dagger}$ & $0.491^{* * *}$ & $0^{\dagger}$ & 0.002 & $0.043^{* *}$ \\
& $(0)$ & $(0)$ & $(0.070)$ & $(0)$ & $(0.002)$ & $(0.020)$ \\
Earnings & $0.412^{* * *}$ & $0^{\dagger}$ & 0.198 & $0.562^{* * *}$ & $0^{\dagger}$ & $0^{\dagger}$ \\
& $(0.146)$ & $(0)$ & $(0.320)$ & $(0.089)$ & $(0)$ & $(0)$ \\
Emp & $7.426^{* * *}$ & $0^{\dagger}$ & $0^{\dagger}$ & $0^{\dagger}$ & $0.645^{* * *}$ & $0^{\dagger}$ \\
& $(0.830)$ & $(0)$ & $(0)$ & $(0)$ & $(0.040)$ & $(0)$ \\
Price & $0^{\dagger}$ & $0^{\dagger}$ & $0^{\dagger}$ & $0^{\dagger}$ & $0.022^{* * *}$ & $0.561^{* * *}$ \\
& 0 & $(0)$ & $(0)$ & $(0)$ & $(0.007)$ & $(0.085)$ \\
\hline
\end{tabular}

Notes: Standard errors in parentheses. ${ }^{*},{ }^{*}$, and $* * *$ indicate statistical significance at the $10 \%, 5 \%$, and $1 \%$ level, respectively. $\dagger$ indicates that the relationship is constrained to be equal to zero. Variables are Churn, Job Creation (JC), Job Destruction (JD), LEHD Earnings, Employment (Emp), and Price Level. 
Table D7: Small Model Plus GDP, No Parameter Restrictions, Using LEHD Earnings

\begin{tabular}{rllllll}
\hline \hline & \multicolumn{6}{c}{ Effect of: } \\
\cline { 2 - 7 } Effect on: & Churn & JC & JD & Earnings & Emp & GDP \\
\hline Churn & $0.819^{* * *}$ & 0.073 & -0.097 & 0.041 & $-0.017^{* * *}$ & $1.648^{* * *}$ \\
& $(0.119)$ & $(0.302)$ & $(0.184)$ & $(0.037)$ & $(0.005)$ & $(0.541)$ \\
JC & $0.142^{* *}$ & $0.269^{*}$ & 0.093 & 0.017 & $-0.012^{* * *}$ & $0.694^{* *}$ \\
& $(0.060)$ & $(0.152)$ & $(0.093)$ & $(0.018)$ & $(0.002)$ & $(0.272)$ \\
JD & -0.042 & -0.091 & $0.364^{* * *}$ & -0.001 & $0.010^{* *}$ & -0.413 \\
& $(0.084)$ & $(0.214)$ & $(0.131)$ & $(0.026)$ & $(0.004)$ & $(0.384)$ \\
Earnings & 0.347 & 0.829 & $1.310^{* *}$ & $0.509^{* * *}$ & $-0.032^{* *}$ & $3.281^{* *}$ \\
& $(0.309)$ & $(0.786)$ & $(0.480)$ & $(0.096)$ & $(0.013)$ & $(1.408)$ \\
Emp & $3.417^{* *}$ & 1.980 & -1.972 & 0.608 & $0.620^{* * *}$ & $18.917^{* * *}$ \\
& $(1.582)$ & $(4.023)$ & $(2.454)$ & $(0.490)$ & $(0.066)$ & $(7.207)$ \\
GDP & 0.038 & 0.048 & -0.042 & 0.010 & -0.001 & $0.708^{* * *}$ \\
& $(0.027)$ & $(0.070)$ & $(0.042)$ & $(0.008)$ & $(0.001)$ & $(0.125)$ \\
\hline
\end{tabular}

Notes: Standard errors in parentheses. ${ }^{*},{ }^{* *}$, and ${ }^{* * *}$ indicate statistical significance at the $10 \%, 5 \%$, and $1 \%$ level, respectively. $\dagger$ indicates that the relationship is constrained to be equal to zero. Variables are Churn, Job Creation (JC), Job Destruction (JD), LEHD Earnings, Employment (Emp), and GDP. 
Table D8: Small Model Plus GDP, With Parameter Restrictions, Using LEHD Earnings

\begin{tabular}{rllllll}
\hline \hline & \multicolumn{5}{c}{ Effect of: } \\
\cline { 2 - 7 } Effect on: & Churn & JC & JD & Earnings & Emp & GDP \\
\hline Churn & $0.831^{* * *}$ & $0^{\dagger}$ & $0^{\dagger}$ & $0^{\dagger}$ & $-0.012^{* * *}$ & $1.359^{* * *}$ \\
& $(0.085)$ & $(0)$ & $(0)$ & $(0)$ & $(0.003)$ & $(0.456)$ \\
JC & $0.120^{* * *}$ & $0.185^{* *}$ & $0^{\dagger}$ & $0^{\dagger}$ & $-0.008^{* * *}$ & $0.504^{* *}$ \\
& $(0.043)$ & $(0.092)$ & $(0)$ & $(0)$ & $(0.002)$ & $(0.204)$ \\
JD & $0^{\dagger}$ & $0^{\dagger}$ & $0.506^{* * *}$ & $0^{\dagger}$ & $0.004^{* * *}$ & $0^{\dagger}$ \\
& $(0)$ & $(0)$ & $(0.070)$ & $(0)$ & $(0.001)$ & $(0)$ \\
Earnings & $0^{\dagger}$ & $0^{\dagger}$ & $0.733^{* *}$ & $0.540^{* * *}$ & $-0.022^{* *}$ & $4.355^{* * *}$ \\
& $(0)$ & $(0)$ & $(0.367)$ & $(0.085)$ & $(0.011)$ & $(1.134)$ \\
Emp & $4.516^{* * *}$ & $0^{\dagger}$ & $0^{\dagger}$ & $0^{\dagger}$ & $0.631^{* * *}$ & $18.180^{* * *}$ \\
& $(1.292)$ & $(0)$ & $(0)$ & $(0)$ & $(0.041)$ & $(6.975)$ \\
GDP & $0.053^{* *}$ & $0^{\dagger}$ & $0^{\dagger}$ & $0^{\dagger}$ & $0^{\dagger}$ & $0.621^{* * *}$ \\
& $(0.022)$ & $(0)$ & $(0)$ & $(0)$ & $(0)$ & $(0.114)$ \\
\hline
\end{tabular}

Notes: Standard errors in parentheses. ${ }^{*},{ }^{* *}$, and ${ }^{* * *}$ indicate statistical significance at the $10 \%, 5 \%$, and $1 \%$ level, respectively. $\dagger$ indicates that the relationship is constrained to be equal to zero. Variables are Churn, Job Creation (JC), Job Destruction (JD), LEHD Earnings, Employment (Emp), and GDP. 


\section{E Impulse-Response Charts (For Web Appendix)}




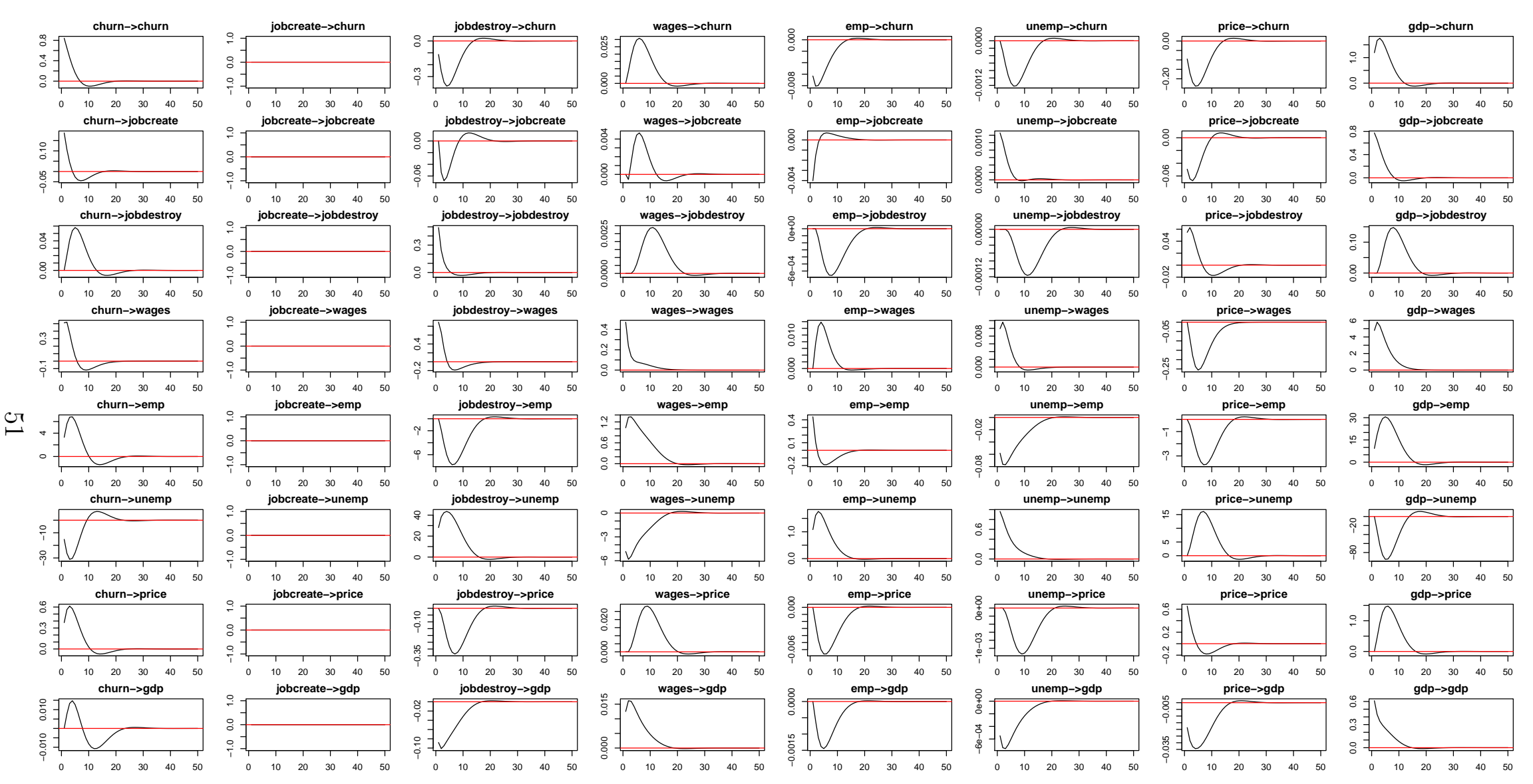

Figure F1: Impulse response functions for cycle components of Labor data, 1993.Q2 through 2013.Q4. 


\section{F Detailed Tables of VAR Results with Alternative Earnings Measures (For Web Appendix)}


Table E1: Full model, No Parameter Restrictions, Using CES Weekly Earnings

\begin{tabular}{rllllllll}
\hline \hline & \multicolumn{7}{c}{ Effect of: } \\
\cline { 2 - 8 } Effect on: & Churn & JC & JD & Earnings & Emp & UR & Price & GDP \\
\hline Churn & $0.817^{* * *}$ & -0.075 & -0.234 & 0.012 & $-0.012^{*}$ & -0.001 & $-0.094^{* * *}$ & $1.467^{* *}$ \\
& $(0.116)$ & $(0.300)$ & $(0.195)$ & $(0.060)$ & $(0.007)$ & $(0.002)$ & $(0.036)$ & $(0.577)$ \\
JC & $0.172^{* * *}$ & 0.127 & -0.015 & 0.016 & $-0.006^{* *}$ & 0.001 & $-0.039^{* *}$ & $0.796^{* * *}$ \\
& $(0.058)$ & $(0.149)$ & $(0.097)$ & $(0.030)$ & $(0.003)$ & $(0.001)$ & $(0.018)$ & $(0.288)$ \\
JD & -0.040 & -0.076 & $0.341^{* *}$ & $0.092^{* *}$ & 0.005 & -0.001 & $0.067^{* * *}$ & $-0.696^{*}$ \\
& $(0.083)$ & $(0.213)$ & $(0.139)$ & $(0.042)$ & $(0.005)$ & $(0.001)$ & $(0.025)$ & $(0.411)$ \\
Earnings & 0.228 & -0.450 & -0.070 & $0.751^{* * *}$ & 0.003 & $0.006^{* *}$ & 0.093 & 0.995 \\
& $(0.199)$ & $(0.514)$ & $(0.335)$ & $(0.102)$ & $(0.011)$ & $(0.003)$ & $(0.061)$ & $(0.991)$ \\
Emp & $2.915^{*}$ & 4.482 & -1.379 & $1.449^{*}$ & $0.463^{* * *}$ & $-0.057^{* * *}$ & $0.790^{*}$ & 8.931 \\
& $(1.554)$ & $(4.011)$ & $(2.611)$ & $(0.798)$ & $(0.088)$ & $(0.022)$ & $(0.477)$ & $(7.732)$ \\
UR & $-14.106^{*}$ & -15.410 & $31.044^{* *}$ & -4.210 & $0.938^{* *}$ & $0.938^{* * *}$ & 0.549 & -24.293 \\
& $(7.389)$ & $(19.071)$ & $(12.414)$ & $(3.796)$ & $(0.419)$ & $(0.103)$ & $(2.269)$ & $(36.762)$ \\
Price & -0.516 & 0.974 & -0.575 & 0.033 & 0.015 & -0.004 & $0.623^{* * *}$ & 0.679 \\
& $(0.344)$ & $(0.887)$ & $(0.577)$ & $(0.177)$ & $(0.019)$ & $(0.005)$ & $(0.105)$ & $(1.710)$ \\
GDP & 0.033 & 0.032 & -0.064 & 0.007 & -0.001 & $-0.001^{* * *}$ & $-0.016^{* *}$ & $0.615^{* * *}$ \\
& $(0.027)$ & $(0.070)$ & $(0.045)$ & $(0.014)$ & $(0.002)$ & $(0.000)$ & $(0.008)$ & $(0.134)$ \\
\hline
\end{tabular}

Notes: Standard errors in parentheses. ${ }^{*},{ }^{* *}$, and $* * *$ indicate statistical significance at the $10 \%, 5 \%$, and $1 \%$ level, respectively. $\dagger$ indicates that the relationship is constrained to be equal to zero. Variables are Churn, Job Creation (JC), Job Destruction (JD), CES Earnings, Employment (Emp), Unemployment Rate (UR), Price Level, and GDP. 
Table E2: Full Model, with Parameter Restrictions, Using CES Weekly Earnings

\begin{tabular}{rllllllll}
\hline \hline & \multicolumn{7}{c}{ Effect of: } \\
\cline { 2 - 9 } Effect on: & Churn & JC & JD & Earnings & Emp & UR & Price & GDP \\
\hline Churn & $0.928^{* * *}$ & $0^{\dagger}$ & -0.053 & 0 & $-0.011^{* * *}$ & $0^{\dagger}$ & $-0.074^{* * *}$ & $1.051^{* * *}$ \\
& $(0.081)$ & $(0)$ & $(0.113)$ & $(0)$ & $(0.004)$ & $(0)$ & $(0.024)$ & $(0.385)$ \\
JC & $0.182^{* * *}$ & $0^{\dagger}$ & $0^{\dagger}$ & $0^{\dagger}$ & $-0.007^{* * *}$ & 0.001 & $-0.044^{* * *}$ & $0.920^{* * *}$ \\
& $(0.036)$ & $(0)$ & $(0)$ & $(0)$ & $(0.002)$ & $(0.001)$ & $(0.013)$ & $(0.217)$ \\
JD & $0^{\dagger}$ & $0^{\dagger}$ & $0.324^{* * *}$ & $0.099^{* * *}$ & $0.008^{* * *}$ & $0^{\dagger}$ & $0.069^{* * *}$ & $-0.766^{* * *}$ \\
& $(0)$ & $(0)$ & $(0.079)$ & $(0.029)$ & $(0.003)$ & $(0)$ & $(0.022)$ & $(0.265)$ \\
Earnings & $0^{\dagger}$ & $0^{\dagger}$ & $0^{\dagger}$ & $0.781^{* * *}$ & $0^{\dagger}$ & $0.002^{* *}$ & $0.091^{*}$ & $0^{\dagger}$ \\
& $(0)$ & $(0)$ & $(0)$ & $(0.063)$ & $(0)$ & $(0.001)$ & $(0.051)$ & $(0)$ \\
Emp & $6.34^{* * *}$ & $0^{\dagger}$ & $0^{\dagger}$ & $1.188^{* *}$ & $0.451^{* * *}$ & $-0.047^{* * *}$ & $0.930^{* * *}$ & $0^{\dagger}$ \\
& $(1.003)$ & $(0)$ & $(0)$ & $(0.528)$ & $(0.065)$ & $(0.017)$ & $(0.357)$ & $(0)$ \\
UR & $-26.861^{* * *}$ & $0^{\dagger}$ & $22.076^{* * *}$ & $0^{\dagger}$ & $0.964^{* * *}$ & $0.870^{* * *}$ & $0^{\dagger}$ & $0^{\dagger}$ \\
& $(5.134)$ & $(0)$ & $(7.035)$ & $(0)$ & $(0.306)$ & $(0.076)$ & $(0)$ & $(0)$ \\
Price & $0.409^{* * *}$ & $0^{\dagger}$ & $0^{\dagger}$ & $0^{\dagger}$ & $0^{\dagger}$ & $0^{\dagger}$ & $0.663^{* * *}$ & $0^{\dagger}$ \\
& $(0.110)$ & $(0)$ & $(0)$ & $(0)$ & $(0)$ & $(0)$ & $(0.073)$ & $(0)$ \\
GDP & $0.062^{* * *}$ & $0^{\dagger}$ & $-0.052^{* *}$ & $0^{\dagger}$ & $0^{\dagger}$ & $0^{\dagger}$ & $-0.017^{* * *}$ & $0.509^{* * *}$ \\
& $(0.021)$ & $(0)$ & $(0.025)$ & $(0)$ & $(0)$ & $(0)$ & $(0.005)$ & $(0.096)$ \\
\hline
\end{tabular}

Notes: Standard errors in parentheses. ***, and *** indicate statistical significance at the $10 \%, 5 \%$, and $1 \%$ level, respectively. $\dagger$ indicates that the relationship is constrained to be equal to zero. Variables are Churn, Job Creation (JC), Job Destruction (JD), CES Earnings, Employment (Emp), Unemployment Rate (UR), Price Level, and GDP. 
Table E3: Small Model, No Parameter Restrictions, Using CES Weekly Earnings

\begin{tabular}{rlllll}
\hline \hline & \multicolumn{5}{c}{ Effect of: } \\
\cline { 2 - 6 } Effect on: & Churn & JC & JD & Earnings & Emp \\
\hline Churn & $0.987^{* * *}$ & 0.123 & -0.273 & $0.109^{* *}$ & -0.008 \\
& $(0.111)$ & $(0.318)$ & $(0.210)$ & $(0.054)$ & $(0.005)$ \\
JC & $0.214^{* * *}$ & 0.237 & -0.020 & $0.067^{* * *}$ & $-0.008^{* * *}$ \\
& $(0.054)$ & $(0.155)$ & $(0.102)$ & $(0.026)$ & $(0.002)$ \\
JD & -0.079 & -0.198 & $0.331^{* *}$ & 0.021 & $0.009^{* * *}$ \\
& $(0.077)$ & $(0.219)$ & $(0.145)$ & $(0.037)$ & $(0.003)$ \\
Earnings & 0.112 & -0.387 & -0.068 & $0.724^{* * *}$ & -0.007 \\
& $(0.183)$ & $(0.525)$ & $(0.347)$ & $(0.088)$ & $(0.008)$ \\
Emp & $5.395^{* * *}$ & 4.258 & -2.830 & 0.683 & $0.719^{* * *}$ \\
& $(1.492)$ & $(4.272)$ & $(2.821)$ & $(0.718)$ & $(0.064)$ \\
\hline
\end{tabular}

Notes: Standard errors in parentheses. ${ }^{*},{ }^{* *}$, and ${ }^{* * *}$ indicate statistical significance at the $10 \%, 5 \%$, and $1 \%$ level, respectively. $\dagger$ indicates that the relationship is constrained to be equal to zero. Variables are Churn, Job Creation (JC), Job Destruction (JD), CES Earnings, and Employment (Emp).

Table E4: Small Model, with Parameter Restrictions, Using CES Weekly Earnings

\begin{tabular}{rlllll}
\hline \hline & \multicolumn{5}{c}{ Effect of: } \\
\cline { 2 - 6 } Effect on: & Churn & JC & JD & Earnings & Emp \\
\hline Churn & $1.066^{* * *}$ & $0^{\dagger}$ & $0^{\dagger}$ & $0.071^{* *}$ & $-0.012^{* * *}$ \\
& $(0.059)$ & $(0)$ & $(0)$ & $(0.035)$ & $(0.003)$ \\
JC & $0.248^{* * *}$ & $0^{\dagger}$ & $0^{\dagger}$ & $0.074^{* * *}$ & $-0.009^{* * *}$ \\
& $(0.027)$ & $(0)$ & $(0)$ & $(0.017)$ & $(0.001)$ \\
JD & $0^{\dagger}$ & $0^{\dagger}$ & $0.440^{* * *}$ & $0^{\dagger}$ & $0.005^{* * *}$ \\
& $(0)$ & $(0)$ & $(0.067)$ & $(0)$ & $(0.001)$ \\
Earnings & $0^{\dagger}$ & $0^{\dagger}$ & $0^{\dagger}$ & $0.730^{* * *}$ & $0^{\dagger}$ \\
& $(0)$ & $(0)$ & $(0)$ & $(0.072)$ & $(0)$ \\
Emp & $7.812^{* * *}$ & $0^{\dagger}$ & $0^{\dagger}$ & $0^{\dagger}$ & $0.620^{* * *}$ \\
& $(0.880)$ & $(0)$ & $(0)$ & $(0)$ & $(0.045)$ \\
\hline
\end{tabular}

Notes: Standard errors in parentheses. *, **, and *** indicate statistical significance at the $10 \%, 5 \%$, and $1 \%$ level, respectively. $\dagger$ indicates that the relationship is constrained to be equal to zero. Variables are Churn, Job Creation (JC), Job Destruction (JD), CES Earnings, and Employment (Emp). 
Table E5: Small Model Plus the Unemployment Rate, No Parameter Restrictions, Using CES Weekly Earnings

\begin{tabular}{rllllll}
\hline \hline & \multicolumn{6}{c}{ Effect of: } \\
\cline { 2 - 7 } Effect on: & Churn & JC & JD & Earnings & Emp & UR \\
\hline Churn & $0.903^{* * *}$ & 0.143 & -0.237 & $0.122^{* *}$ & $-0.016^{* *}$ & -0.003 \\
& $(0.120)$ & $(0.313)$ & $(0.208)$ & $(0.053)$ & $(0.007)$ & $(0.002)$ \\
JC & $0.218^{* * *}$ & 0.236 & -0.022 & $0.066^{* *}$ & $-0.008^{* * *}$ & 0.000 \\
& $(0.059)$ & $(0.155)$ & $(0.103)$ & $(0.026)$ & $(0.003)$ & $(0.001)$ \\
JD & -0.084 & -0.197 & $0.333^{* *}$ & 0.021 & $0.009^{*}$ & 0.000 \\
& $(0.084)$ & $(0.219)$ & $(0.145)$ & $(0.037)$ & $(0.005)$ & $(0.001)$ \\
Earnings & 0.274 & -0.425 & -0.137 & $0.698^{* * *}$ & 0.009 & $0.005^{*}$ \\
& $(0.196)$ & $(0.512)$ & $(0.340)$ & $(0.087)$ & $(0.011)$ & $(0.003)$ \\
Emp & $3.330^{* *}$ & 4.743 & -1.961 & 1.010 & $0.513^{* * *}$ & $-0.067^{* * *}$ \\
& $(1.536)$ & $(4.018)$ & $(2.665)$ & $(0.682)$ & $(0.086)$ & $(0.020)$ \\
UR & $-15.459^{* *}$ & -18.231 & $31.521^{* *}$ & $-5.215^{*}$ & $0.952^{* *}$ & $0.967^{* * *}$ \\
& $(7.131)$ & $(18.660)$ & $(12.376)$ & $(3.168)$ & $(0.401)$ & $(0.094)$ \\
\hline
\end{tabular}

Notes: Standard errors in parentheses. ${ }^{*},{ }^{* *}$, and ${ }^{* * *}$ indicate statistical significance at the $10 \%, 5 \%$, and $1 \%$ level, respectively. $\dagger$ indicates that the relationship is constrained to be equal to zero. Variables are Churn, Job Creation (JC), Job Destruction (JD), CES Earnings, Employment (Emp), and Unemployment Rate (UR). 
Table E6: Small Model Plus the Unemployment Rate, with Parameter Restrictions, Using CES Weekly Earnings

\begin{tabular}{rllllll}
\hline \hline & \multicolumn{7}{c}{ Effect of: } \\
\cline { 2 - 7 } Effect on: & Churn & JC & JD & Earnings & Emp & UR \\
\hline Churn & $1.073^{* * *}$ & $0^{\dagger}$ & $0^{\dagger}$ & 0.053 & $-0.012^{* * *}$ & $0^{\dagger}$ \\
& $(0.059)$ & $(0)$ & $(0)$ & $(0.035)$ & $(0.003)$ & $(0)$ \\
JC & $0.249^{* * *}$ & $0^{\dagger}$ & $0^{\dagger}$ & $0.069^{* * *}$ & $-0.009^{* * *}$ & $0^{\dagger}$ \\
& $(0.027)$ & $(0)$ & $(0)$ & $(0.016)$ & $(0.001)$ & $(0)$ \\
JD & $0^{\dagger}$ & $0^{\dagger}$ & $0.447^{* * *}$ & $0^{\dagger}$ & $0.005^{* * *}$ & $0^{\dagger}$ \\
& $(0)$ & $(0)$ & $(0.067)$ & $(0)$ & $(0.001)$ & $(0)$ \\
Earnings & $0^{\dagger}$ & $0^{\dagger}$ & $0^{\dagger}$ & $0.699^{* * *}$ & $0^{\dagger}$ & 0.001 \\
& $(0)$ & $(0)$ & $(0)$ & $(0.073)$ & $(0)$ & $(0.001)$ \\
Emp & $6.381^{* * *}$ & $0^{\dagger}$ & $0^{\dagger}$ & $0^{\dagger}$ & $0.497^{* * *}$ & $-0.043^{* *}$ \\
& $(1.018)$ & $(0)$ & $(0)$ & $(0)$ & $(0.068)$ & $(0.018)$ \\
UR & $-26.201^{* * *}$ & $0^{\dagger}$ & $22.131^{* * *}$ & $0^{\dagger}$ & $0.983^{* * *}$ & $0.872^{* * *}$ \\
& $(5.100)$ & $(0)$ & $(6.998)$ & $(0)$ & $(0.341)$ & $(0.079)$ \\
\hline
\end{tabular}

Notes: Standard errors in parentheses. ${ }^{*}, * *$, and $* * *$ indicate statistical significance at the $10 \%, 5 \%$, and $1 \%$ level, respectively. $\dagger$ indicates that the relationship is constrained to be equal to zero. Variables are Churn, Job Creation (JC), Job Destruction (JD), CES Earnings, Employment (Emp), and Unemployment Rate (UR). 
Table E7: Small model Plus the Price Level, no parameter restrictions, Using CES Weekly Earnings

\begin{tabular}{rllllll}
\hline \hline & \multicolumn{6}{c}{ Effect of: } \\
\cline { 2 - 7 } Effect on: & Churn & JC & JD & Earnings & Emp & Price \\
\hline Churn & $0.977^{* * *}$ & 0.056 & -0.307 & 0.038 & -0.003 & $-0.087^{* *}$ \\
& $(0.108)$ & $(0.310)$ & $(0.204)$ & $(0.060)$ & $(0.005)$ & $(0.037)$ \\
JC & $0.210^{* * *}$ & 0.211 & -0.034 & 0.039 & $-0.006^{* * *}$ & $-0.034^{*}$ \\
& $(0.053)$ & $(0.153)$ & $(0.101)$ & $(0.030)$ & $(0.002)$ & $(0.018)$ \\
JD & -0.071 & -0.150 & $0.356^{* *}$ & $0.071^{*}$ & $0.006^{* *}$ & $0.063^{* *}$ \\
& $(0.074)$ & $(0.213)$ & $(0.140)$ & $(0.041)$ & $(0.003)$ & $(0.026)$ \\
Earnings & 0.124 & -0.307 & -0.028 & $0.807^{* * *}$ & -0.012 & 0.102 \\
& $(0.181)$ & $(0.519)$ & $(0.342)$ & $(0.101)$ & $(0.008)$ & $(0.063)$ \\
Emp & $5.490^{* * *}$ & 4.877 & -2.514 & 1.330 & $0.677^{* * *}$ & 0.799 \\
& $(1.472)$ & $(4.229)$ & $(2.788)$ & $(0.820)$ & $(0.068)$ & $(0.511)$ \\
Price & -0.327 & 1.005 & -0.658 & 0.025 & $0.031^{* *}$ & $0.624^{* * *}$ \\
& $(0.305)$ & $(0.876)$ & $(0.578)$ & $(0.170)$ & $(0.014)$ & $(0.106)$ \\
\hline
\end{tabular}

Notes: Standard errors in parentheses. ${ }^{*}, * *$, and ${ }^{* * *}$ indicate statistical significance at the $10 \%, 5 \%$, and $1 \%$ level, respectively. $\dagger$ indicates that the relationship is constrained to be equal to zero. Variables are Churn, Job Creation (JC), Job Destruction (JD), CES Earnings, Employment (Emp), and Price Level. 
Table E8: Small Model Plus the Price Level, with Parameter Restrictions, Using CES Weekly Earnings

\begin{tabular}{rllllll}
\hline \hline & \multicolumn{6}{c}{ Effect of: } \\
\cline { 2 - 7 } Effect on: & Churn & JC & JD & Earnings & Emp & Price \\
\hline Churn & $0.943^{* * *}$ & $0^{\dagger}$ & -0.157 & $0^{\dagger}$ & $0^{\dagger}$ & $-0.117^{* * *}$ \\
& $(0.043)$ & $(0)$ & $(0.097)$ & $(0)$ & $(0)$ & $(0.027)$ \\
JC & $0.163^{* * *}$ & $0.249^{* * *}$ & $0^{\dagger}$ & $0^{\dagger}$ & $-0.004^{* *}$ & $-0.054^{* * *}$ \\
& $(0.036)$ & $(0.090)$ & $(0)$ & $(0)$ & $(0.002)$ & $(0.015)$ \\
JD & $0^{\dagger}$ & $0^{\dagger}$ & $0.448^{* * *}$ & $0.093^{* * *}$ & 0.001 & $0.088^{* * *}$ \\
& $(0)$ & $(0)$ & $(0.068)$ & $(0.028)$ & $(0.002)$ & $(0.023)$ \\
Earnings & $0^{\dagger}$ & $0^{\dagger}$ & $0^{\dagger}$ & $0.798^{* * *}$ & $-0.009^{* *}$ & $0.107^{*}$ \\
& $(0)$ & $(0)$ & $(0)$ & $(0.068)$ & $(0.004)$ & $(0.057)$ \\
Emp & $7.407^{* * *}$ & $0^{\dagger}$ & $0^{\dagger}$ & $1.171^{*}$ & $0.627^{* * *}$ & 0.594 \\
& $(0.819)$ & $(0)$ & $(0)$ & $(0.637)$ & $(0.046)$ & $(0.477)$ \\
Price & $0^{\dagger}$ & $0^{\dagger}$ & $0^{\dagger}$ & $0^{\dagger}$ & $0.022^{* * *}$ & $0.586^{* * *}$ \\
& $(0)$ & $(0)$ & $(0)$ & $(0)$ & $(0.007)$ & $(0.088)$ \\
\hline
\end{tabular}

Notes: Standard errors in parentheses. ${ }^{*},{ }^{*}$, and $* * *$ indicate statistical significance at the $10 \%, 5 \%$, and $1 \%$ level, respectively. $\dagger$ indicates that the relationship is constrained to be equal to zero. Variables are Churn, Job Creation (JC), Job Destruction (JD), CES Earnings, Employment (Emp), and Price Level. 
Table E9: Small Model Plus GDP, No Parameter Restrictions, Using CES Weekly Earnings

\begin{tabular}{rllllll}
\hline \hline & \multicolumn{6}{c}{ Effect of: } \\
\cline { 2 - 7 } Effect on: & Churn & JC & JD & Earnings & Emp & GDP \\
\hline Churn & $0.853^{* * *}$ & -0.011 & -0.207 & 0.083 & $-0.014^{* * *}$ & $1.494^{* * *}$ \\
& $(0.117)$ & $(0.309)$ & $(0.203)$ & $(0.052)$ & $(0.005)$ & $(0.546)$ \\
JC & $0.161^{* * *}$ & 0.184 & 0.006 & $0.057^{* *}$ & $-0.010^{* * *}$ & $0.588^{* *}$ \\
& $(0.058)$ & $(0.153)$ & $(0.100)$ & $(0.026)$ & $(0.003)$ & $(0.270)$ \\
JD & -0.037 & -0.156 & $0.311^{* *}$ & 0.029 & $0.011^{* * *}$ & -0.467 \\
& $(0.084)$ & $(0.220)$ & $(0.144)$ & $(0.037)$ & $(0.004)$ & $(0.389)$ \\
Earnings & 0.096 & -0.402 & -0.061 & $0.721^{* * *}$ & -0.008 & 0.169 \\
& $(0.202)$ & $(0.531)$ & $(0.349)$ & $(0.090)$ & $(0.009)$ & $(0.940)$ \\
Emp & $3.755^{* *}$ & 2.614 & -2.025 & 0.368 & $0.640^{* * *}$ & $18.274^{* *}$ \\
& $(1.586)$ & $(4.176)$ & $(2.742)$ & $(0.705)$ & $(0.069)$ & $(7.383)$ \\
GDP & $0.046^{*}$ & 0.036 & -0.062 & 0.017 & -0.001 & $0.677^{* * *}$ \\
& $(0.027)$ & $(0.071)$ & $(0.047)$ & $(0.012)$ & $(0.001)$ & $(0.126)$ \\
\hline
\end{tabular}

Notes: Standard errors in parentheses. ${ }^{*}, * *$, and $* * *$ indicate statistical significance at the $10 \%, 5 \%$, and $1 \%$ level, respectively. $\dagger$ indicates that the relationship is constrained to be equal to zero. Variables are Churn, Job Creation (JC), Job Destruction (JD), CES Earnings, Employment (Emp), and GDP. 
Table E10: Small Model Plus GDP, with Parameter Restrictions, Using CES Weekly Earnings

\begin{tabular}{rllllll}
\hline \hline & \multicolumn{7}{c}{ Effect of: } \\
\cline { 2 - 7 } Effect on: & Churn & JC & JD & Earnings & Emp & GDP \\
\hline Churn & $0.845^{* * *}$ & $0^{\dagger}$ & $0^{\dagger}$ & $0^{\dagger}$ & $-0.012^{* * *}$ & $1.268^{* * *}$ \\
& $(0.085)$ & $(0)$ & $(0)$ & $(0)$ & $(0.003)$ & $(0.452)$ \\
JC & $0.179^{* * *}$ & $0^{\dagger}$ & $0^{\dagger}$ & $0.057^{* * *}$ & $-0.009^{* * *}$ & $0.429^{* *}$ \\
& $(0.035)$ & $(0)$ & $(0)$ & $(0.016)$ & $(0.001)$ & $(0.190)$ \\
JD & $0^{\dagger}$ & $0^{\dagger}$ & $0.442^{* * *}$ & $0^{\dagger}$ & $0.004^{* * *}$ & $0^{\dagger}$ \\
& $(0)$ & $(0)$ & $(0.066)$ & $(0)$ & $(0.001)$ & $(0)$ \\
Earnings & $0^{\dagger}$ & $0^{\dagger}$ & $0^{\dagger}$ & $0.732^{* * *}$ & $0^{\dagger}$ & $0^{\dagger}$ \\
& $(0)$ & $(0)$ & $(0)$ & $(0.071)$ & $(0)$ & $(0)$ \\
Emp & $4.592^{* * *}$ & $0^{\dagger}$ & $0^{\dagger}$ & $0^{\dagger}$ & $0.624^{* * *}$ & $18.106^{* * *}$ \\
& $(1.285)$ & $(0)$ & $(0)$ & $(0)$ & $(0.040)$ & $(6.936)$ \\
GDP & $0.054^{* *}$ & $0^{\dagger}$ & $0^{\dagger}$ & $0^{\dagger}$ & $0^{\dagger}$ & $0.608^{* * *}$ \\
& $(0.022)$ & $(0)$ & $(0)$ & $(0)$ & $(0)$ & $(0.114)$ \\
\hline
\end{tabular}

Notes: Standard errors in parentheses. ${ }^{*},{ }^{* *}$, and ${ }^{* * *}$ indicate statistical significance at the $10 \%, 5 \%$, and $1 \%$ level, respectively. $\dagger$ indicates that the relationship is constrained to be equal to zero. Variables are Churn, Job Creation (JC), Job Destruction (JD), CES Earnings, Employment (Emp), and GDP. 
Table E11: Full Model, No Parameter Restrictions, Using CPS Median Earnings

\begin{tabular}{rllllllll}
\hline \hline & \multicolumn{7}{c}{ Effect of: } \\
\cline { 2 - 8 } Effect on: & Churn & JC & JD & Earnings & Emp & UR & Price & GDP \\
\hline Churn & $0.819^{* * *}$ & -0.073 & -0.244 & 0.035 & $-0.014^{* *}$ & -0.002 & $-0.086^{* *}$ & $1.391^{* *}$ \\
& $(0.116)$ & $(0.291)$ & $(0.186)$ & $(0.049)$ & $(0.007)$ & $(0.002)$ & $(0.035)$ & $(0.575)$ \\
JC & $0.169^{* * *}$ & 0.150 & 0.013 & -0.013 & -0.005 & $0.002^{* *}$ & $-0.048^{* * *}$ & $0.880^{* * *}$ \\
& $(0.058)$ & $(0.146)$ & $(0.093)$ & $(0.025)$ & $(0.004)$ & $(0.001)$ & $(0.017)$ & $(0.287)$ \\
JD & -0.047 & 0.022 & $0.432^{* * *}$ & 0.018 & 0.005 & -0.001 & $0.045^{*}$ & -0.511 \\
& $(0.085)$ & $(0.214)$ & $(0.136)$ & $(0.036)$ & $(0.005)$ & $(0.001)$ & $(0.025)$ & $(0.422)$ \\
Earnings & -0.170 & 0.267 & $0.698^{*}$ & $0.494^{* * *}$ & $0.035^{* *}$ & $0.008^{* *}$ & -0.071 & 0.493 \\
& $(0.250)$ & $(0.631)$ & $(0.402)$ & $(0.107)$ & $(0.016)$ & $(0.004)$ & $(0.075)$ & $(1.245)$ \\
Emp & $2.851^{*}$ & 5.875 & -0.277 & 0.768 & $0.422^{* * *}$ & $-0.065^{* *}$ & 0.598 & 10.331 \\
& $(1.572)$ & $(3.96)$ & $(2.522)$ & $(0.670)$ & $(0.100)$ & $(0.026)$ & $(0.469)$ & $(7.814)$ \\
UR & $-13.243^{*}$ & -21.797 & $22.777^{*}$ & 4.966 & 0.553 & $0.800^{* * *}$ & 3.436 & -50.636 \\
& $(7.330)$ & $(18.466)$ & $(11.763)$ & $(3.125)$ & $(0.469)$ & $(0.121)$ & $(2.187)$ & $(36.443)$ \\
Price & -0.515 & 0.995 & -0.572 & 0.050 & 0.012 & -0.005 & $0.629^{* * *}$ & 0.612 \\
& $(0.343)$ & $(0.865)$ & $(0.551)$ & $(0.146)$ & $(0.022)$ & $(0.006)$ & $(0.102)$ & $(1.707)$ \\
GDP & 0.034 & 0.036 & -0.066 & 0.014 & -0.002 & $-0.001^{* * *}$ & $-0.014^{*}$ & $0.591^{* * *}$ \\
& $(0.027)$ & $(0.067)$ & $(0.043)$ & $(0.011)$ & $(0.002)$ & $(0.000)$ & $(0.008)$ & $(0.133)$ \\
\hline
\end{tabular}

Notes: Standard errors in parentheses. ${ }^{*},{ }^{* *}$, and ${ }^{* * *}$ indicate statistical significance at the $10 \%, 5 \%$, and $1 \%$ level, respectively. $\dagger$ indicates that the relationship is constrained to be equal to zero. Variables are Churn, Job Creation (JC), Job Destruction (JD), CPS Median Earnings, Employment (Emp), Unemployment Rate (UR), Price Level, and GDP. 
Table E12: Full Model, with Parameter Restrictions, Using CPS Median Earnings

\begin{tabular}{rllllllll}
\hline \hline \multirow{2}{*}{ Effect on: } & Churn & JC & JD & Earnings & Emp & UR & Price & GDP \\
\hline Churn & $0.886^{* * *}$ & $0^{\dagger}$ & $0^{\dagger}$ & $0^{\dagger}$ & $-0.006^{* *}$ & $0^{\dagger}$ & $-0.112^{* * *}$ & $0.924^{* *}$ \\
& $(0.070)$ & $(0)$ & $(0)$ & $(0)$ & $(0.003)$ & $(0)$ & $(0.024)$ & $(0.359)$ \\
JC & $0.179^{* * *}$ & $0^{\dagger}$ & $0^{\dagger}$ & $0^{\dagger}$ & $0^{\dagger}$ & $0.002^{* * *}$ & $-0.067^{* * *}$ & $0.710^{* * *}$ \\
& $(0.036)$ & $(0)$ & $(0)$ & $(0)$ & $(0)$ & $(0.000)$ & $(0.013)$ & $(0.199)$ \\
JD & $0^{\dagger}$ & $0^{\dagger}$ & $0.428^{* * *}$ & $0^{\dagger}$ & $0^{\dagger}$ & $0^{\dagger}$ & $0.069^{* * *}$ & $0^{\dagger}$ \\
& $(0)$ & $(0)$ & $(0.064)$ & $(0)$ & $(0)$ & $(0)$ & $(0.017)$ & $(0)$ \\
Earnings & $0^{\dagger}$ & $0^{\dagger}$ & $0.521^{* *}$ & $0.571^{* * *}$ & $0.026^{* *}$ & $0.007^{* *}$ & $0^{\dagger}$ & $0^{\dagger}$ \\
& $(0)$ & $(0)$ & $(0.251)$ & $(0.078)$ & $(0.013)$ & $(0.003)$ & $(0)$ & $(0)$ \\
Emp & $3.659^{* * *}$ & $4.607^{* *}$ & $0^{\dagger}$ & $0^{\dagger}$ & $0.534^{* * *}$ & $-0.056^{* * *}$ & $0^{\dagger}$ & $0^{\dagger}$ \\
& $(1.220)$ & $(2.324)$ & $(0)$ & $(0)$ & $(0.058)$ & $(0.015)$ & $(0)$ & $(0)$ \\
UR & $-17.395^{* * *}$ & $0^{\dagger}$ & $28.591^{* * *}$ & $7.398^{* * *}$ & $0^{\dagger}$ & $0.786^{* * *}$ & $6.745^{* * *}$ & $0^{\dagger}$ \\
& $(4.436)$ & $(0)$ & $(6.402)$ & $(1.704)$ & $(0)$ & $(0.053)$ & $(1.385)$ & $(0)$ \\
Price & $0.353^{* * *}$ & $0^{\dagger}$ & $0^{\dagger}$ & $0^{\dagger}$ & $0^{\dagger}$ & $0^{\dagger}$ & $0.637^{* * *}$ & $0^{\dagger}$ \\
& $(0.117)$ & $(0)$ & $(0)$ & $(0)$ & $(0)$ & $(0)$ & $(0.070)$ & $(0)$ \\
GDP & $0^{\dagger}$ & $0^{\dagger}$ & $-0.080^{* * *}$ & $0^{\dagger}$ & $0^{\dagger}$ & $-0.001^{* * *}$ & $-0.026^{* * *}$ & $0.596^{* * *}$ \\
& $(0)$ & $(0)$ & $(0.024)$ & $(0)$ & $(0)$ & $(0)$ & $(0.006)$ & $(0.087)$ \\
\hline
\end{tabular}

Notes: Standard errors in parentheses. * **, and *** indicate statistical significance at the $10 \%, 5 \%$, and $1 \%$ level, respectively. $†$ indicates that the relationship is constrained to be equal to zero. Variables are Churn, Job Creation (JC), Job Destruction (JD), CPS Median Earnings, Employment (Emp), Unemployment Rate (UR), Price Level, and GDP. 
Table E13: Small Model, No Parameter Restrictions, Using CPS Median Earnings

\begin{tabular}{rlllll}
\hline \hline & \multicolumn{5}{c}{ Effect of: } \\
\cline { 2 - 6 } Effect on: & Churn & JC & JD & Earnings & Emp \\
\hline Churn & $1.013^{* * *}$ & 0.265 & -0.182 & 0.060 & $-0.009^{*}$ \\
& $(0.114)$ & $(0.305)$ & $(0.202)$ & $(0.040)$ & $(0.005)$ \\
JC & $0.227^{* *}$ & $0.336^{* *}$ & 0.046 & 0.031 & $-0.009^{* * *}$ \\
& $(0.056)$ & $(0.151)$ & $(0.100)$ & $(0.020)$ & $(0.002)$ \\
JD & -0.087 & -0.115 & $0.397^{* * *}$ & -0.016 & $0.008^{* * *}$ \\
& $(0.078)$ & $(0.208)$ & $(0.137)$ & $(0.028)$ & $(0.003)$ \\
Earnings & -0.301 & 0.399 & $0.757^{*}$ & $0.632^{* * *}$ & 0.008 \\
& $(0.229)$ & $(0.613)$ & $(0.405)$ & $(0.081)$ & $(0.009)$ \\
Emp & $5.210^{* * *}$ & 6.625 & -0.997 & -0.344 & $0.699^{* * *}$ \\
& $(1.519)$ & $(4.063)$ & $(2.686)$ & $(0.538)$ & $(0.062)$ \\
\hline
\end{tabular}

Notes: Standard errors in parentheses. ${ }^{*},{ }^{*}$, and ${ }^{* * *}$ indicate statistical significance at the $10 \%, 5 \%$, and $1 \%$ level, respectively. $\dagger$ indicates that the relationship is constrained to be equal to zero. Variables are Churn, Job Creation (JC), Job Destruction (JD), CPS Median Earnings, and Employment (Emp).

Table E14: Small Model, with Parameter Restrictions, Using CPS Median Earnings

\begin{tabular}{rlllll}
\hline \hline & \multicolumn{5}{l}{ Effect of: } \\
\cline { 2 - 6 } Effect on: & Churn & JC & JD & Earnings & Emp \\
\hline Churn & $1.098^{* * *}$ & $0^{\dagger}$ & $0^{\dagger}$ & $0^{\dagger}$ & $-0.014^{* * *}$ \\
& $(0.062)$ & $(0)$ & $(0)$ & $(0)$ & $(0.003)$ \\
JC & $0.199^{* * *}$ & $0.239^{* * *}$ & $0^{\dagger}$ & $0^{\dagger}$ & $-0.008^{* * *}$ \\
& $(0.039)$ & $(0.091)$ & $(0)$ & $(0)$ & $(0.002)$ \\
JD & $0^{\dagger}$ & $0^{\dagger}$ & $0.538^{* * *}$ & $0^{\dagger}$ & $0.005^{* * *}$ \\
& $(0)$ & $(0)$ & $(0.071)$ & $(0)$ & $(0.001)$ \\
Earnings & $0^{\dagger}$ & $0^{\dagger}$ & $0.816^{* * *}$ & $0.653^{* * *}$ & $0^{\dagger}$ \\
& $(0)$ & $(0)$ & $(0.249)$ & $(0.070)$ & $(0)$ \\
Emp & $7.808^{* * *}$ & $0^{\dagger}$ & $0^{\dagger}$ & $0^{\dagger}$ & $0.622^{* * *}$ \\
& $(0.883)$ & $(0)$ & $(0)$ & $(0)$ & $(0.045)$ \\
\hline
\end{tabular}

Notes: Standard errors in parentheses. ${ }^{*},{ }^{* *}$, and ${ }^{* * *}$ indicate statistical significance at the $10 \%, 5 \%$, and $1 \%$ level, respectively. $\dagger$ indicates that the relationship is constrained to be equal to zero. Variables are Churn, Job Creation (JC), Job Destruction (JD), CPS Median Earnings, and Employment (Emp). 
Table E15: Small Model Plus the Unemployment Rate, No Parameter Restrictions, Using CPS Median Earnings

\begin{tabular}{rllllll}
\hline \hline & \multicolumn{6}{c}{ Effect of: } \\
\cline { 2 - 7 } Effect on: & Churn & JC & JD & Earnings & Emp & UR \\
\hline Churn & $0.900^{* * *}$ & 0.235 & -0.183 & $0.117^{* * *}$ & $-0.023^{* * *}$ & $-0.005^{* *}$ \\
& $(0.119)$ & $(0.294)$ & $(0.194)$ & $(0.045)$ & $(0.007)$ & $(0.002)$ \\
JC & $0.220^{* * *}$ & $0.334^{* *}$ & 0.046 & 0.035 & $-0.010^{* *}$ & 0.000 \\
& $(0.061)$ & $(0.151)$ & $(0.100)$ & $(0.023)$ & $(0.004)$ & $(0.001)$ \\
JD & -0.079 & -0.112 & $0.397^{* * *}$ & -0.021 & $0.010^{* *}$ & 0.000 \\
& $(0.084)$ & $(0.208)$ & $(0.137)$ & $(0.032)$ & $(0.005)$ & $(0.001)$ \\
Earnings & -0.138 & 0.442 & $0.759^{*}$ & $0.549^{* * *}$ & $0.028^{* *}$ & $0.007^{*}$ \\
& $(0.243)$ & $(0.602)$ & $(0.398)$ & $(0.092)$ & $(0.014)$ & $(0.004)$ \\
Emp & $3.354^{* *}$ & 6.129 & -1.015 & 0.591 & $0.474^{* * *}$ & $-0.074^{* * *}$ \\
& $(1.547)$ & $(3.837)$ & $(2.534)$ & $(0.586)$ & $(0.092)$ & $(0.023)$ \\
UR & $-16.238^{* *}$ & $-33.478^{*}$ & $20.257^{*}$ & 1.789 & $0.906^{* *}$ & $0.909^{* * *}$ \\
& $(7.230)$ & $(17.936)$ & $(11.847)$ & $(2.741)$ & $(0.429)$ & $(0.109)$ \\
\hline
\end{tabular}

Notes: Standard errors in parentheses. ${ }^{*},{ }^{* *}$, and ${ }^{* * *}$ indicate statistical significance at the $10 \%, 5 \%$, and $1 \%$ level, respectively. $\dagger$ indicates that the relationship is constrained to be equal to zero. Variables are Churn, Job Creation (JC), Job Destruction (JD), CPS Median Earnings, Employment (Emp), and Unemployment Rate (UR). 
Table E16: Small Model Plus the Unemployment Rate, with Parameter Restrictions, Using CPS Median Earnings

\begin{tabular}{rllllll}
\hline \hline & \multicolumn{5}{c}{ Effect of: } \\
\cline { 2 - 7 } Effect on: & Churn & JC & JD & Earnings & Emp & UR \\
\hline Churn & $0.985^{* * *}$ & $0^{\dagger}$ & $0^{\dagger}$ & $0.073^{* *}$ & $-0.026^{* * *}$ & $-0.004^{* * *}$ \\
& $(0.072)$ & $(0)$ & $(0)$ & $(0.030)$ & $(0.005)$ & $(0.001)$ \\
JC & $0.196^{* * *}$ & $0.237^{* * *}$ & $0^{\dagger}$ & $0^{\dagger}$ & $-0.008^{* * *}$ & $0^{\dagger}$ \\
& $(0.040)$ & $(0.091)$ & $(0)$ & $(0)$ & $(0.002)$ & $(0)$ \\
JD & $0^{\dagger}$ & $0^{\dagger}$ & $0.530^{* * *}$ & $0^{\dagger}$ & $0.004^{* * *}$ & $0^{\dagger}$ \\
& $(0)$ & $(0)$ & $(0.071)$ & $(0)$ & $(0.001)$ & $(0)$ \\
Earnings & $0^{\dagger}$ & $0^{\dagger}$ & $0.651^{* *}$ & $0.569^{* * *}$ & 0.023 & $0.006^{* *}$ \\
& $(0)$ & $(0)$ & $(0.277)$ & $(0.083)$ & $(0.014)$ & $(0.003)$ \\
Emp & $5.709^{* * *}$ & $0^{\dagger}$ & $0^{\dagger}$ & $0^{\dagger}$ & $0.426^{* * *}$ & $-0.065^{* * *}$ \\
& $(1.062)$ & $(0)$ & $(0)$ & $(0)$ & $(0.073)$ & $(0.020)$ \\
UR & $-21.88^{* * *}$ & -6.776 & $21.690^{* * *}$ & $0^{\dagger}$ & $1.252^{* * *}$ & $0.969^{* * *}$ \\
& $(5.963)$ & $(12.000)$ & $(7.778)$ & $(0)$ & $(0.357)$ & $(0.087)$ \\
\hline
\end{tabular}

Notes: Standard errors in parentheses. ${ }^{*}, * *$, and ${ }^{* * *}$ indicate statistical significance at the $10 \%, 5 \%$, and $1 \%$ level, respectively. $\dagger$ indicates that the relationship is constrained to be equal to zero. Variables are Churn, Job Creation (JC), Job Destruction (JD), CPS Median Earnings, Employment (Emp), and Unemployment Rate (UR). 
Table E17: Small Model Plus the Price Level, No Parameter Restrictions, Using CPS Median Earnings

\begin{tabular}{rllllll}
\hline \hline & \multicolumn{5}{c}{ Effect of: } \\
\cline { 2 - 7 } Effect on: & Churn & JC & JD & Earnings & Emp & Price \\
\hline Churn & $0.981^{* * *}$ & 0.103 & -0.274 & 0.012 & -0.003 & $-0.095^{* * *}$ \\
& $(0.110)$ & $(0.299)$ & $(0.197)$ & $(0.043)$ & $(0.005)$ & $(0.036)$ \\
JC & $0.212^{* * *}$ & $0.263^{*}$ & 0.004 & 0.009 & $-0.006^{* * *}$ & $-0.043^{* *}$ \\
& $(0.055)$ & $(0.149)$ & $(0.098)$ & $(0.021)$ & $(0.002)$ & $(0.018)$ \\
JD & -0.073 & -0.043 & $0.438^{*}$ & 0.005 & 0.006 & $0.042^{*}$ \\
& $(0.077)$ & $(0.209)$ & $(0.137)$ & $(0.030)$ & $(0.004)$ & $(0.025)$ \\
Earnings & -0.314 & 0.332 & $0.720^{*}$ & $0.612^{* * *}$ & 0.011 & -0.039 \\
& $(0.230)$ & $(0.625)$ & $(0.411)$ & $(0.089)$ & $(0.011)$ & $(0.075)$ \\
Emp & $5.316^{* * *}$ & $7.164^{*}$ & -0.692 & -0.184 & $0.679^{* * *}$ & 0.316 \\
& $(1.524)$ & $(4.139)$ & $(2.721)$ & $(0.592)$ & $(0.070)$ & $(0.494)$ \\
Price & -0.341 & 1.071 & -0.601 & -0.024 & $0.031^{* *}$ & $0.607^{* * *}$ \\
& $(0.311)$ & $(0.845)$ & $(0.555)$ & $(0.121)$ & $(0.014)$ & $(0.101)$ \\
\hline
\end{tabular}

Notes: Standard errors in parentheses. ${ }^{*},{ }^{* *}$, and ${ }^{* * *}$ indicate statistical significance at the $10 \%, 5 \%$, and $1 \%$ level, respectively. $\dagger$ indicates that the relationship is constrained to be equal to zero. Variables are Churn, Job Creation (JC), Job Destruction (JD), CPS Median Earnings, Employment (Emp), and Price Level. 
Table E18: Small Model Plus the Price Level, with Parameter Restrictions, Using CPS Median Earnings

\begin{tabular}{rllllll}
\hline \hline & \multicolumn{7}{c}{ Effect of: } \\
\cline { 2 - 7 } Effect on: & Churn & JC & JD & Earnings & Emp & Price \\
\hline Churn & $0.989^{* * *}$ & $0^{\dagger}$ & $0^{\dagger}$ & $0^{\dagger}$ & $0^{\dagger}$ & $-0.136^{* * *}$ \\
& $(0.038)$ & $(0)$ & $(0)$ & $(0)$ & $(0)$ & $(0.023)$ \\
JC & $0.173^{* * *}$ & $0.232^{* * *}$ & $0^{\dagger}$ & $0^{\dagger}$ & -0.003 & $-0.063^{* * *}$ \\
& $(0.038)$ & $(0.090)$ & $(0)$ & $(0)$ & $(0.002)$ & $(0.014)$ \\
JD & $0^{\dagger}$ & $0^{\dagger}$ & $0.466^{* * *}$ & $0^{\dagger}$ & $0^{\dagger}$ & $0.067^{* * *}$ \\
& $(0)$ & $(0)$ & $(0.067)$ & $(0)$ & $(0)$ & $(0.016)$ \\
Earnings & $0^{\dagger}$ & $0^{\dagger}$ & $0.600^{* * *}$ & $0.642^{* * *}$ & $0^{\dagger}$ & $0^{\dagger}$ \\
& $(0)$ & $(0)$ & $(0.222)$ & $(0.066)$ & $(0)$ & $(0)$ \\
Emp & $5.267^{* * *}$ & $5.590^{* *}$ & $0^{\dagger}$ & $0^{\dagger}$ & $0.718^{* * *}$ & $0^{\dagger}$ \\
& $(1.222)$ & $(2.800)$ & $(0)$ & $(0)$ & $(0.046)$ & $(0)$ \\
Price & $0^{\dagger}$ & $0^{\dagger}$ & $0^{\dagger}$ & $0^{\dagger}$ & $0.023^{* * *}$ & $0.556^{* * *}$ \\
& $(0)$ & $(0)$ & $(0)$ & $(0)$ & $(0.006)$ & $(0.078)$ \\
\hline
\end{tabular}

Notes: Standard errors in parentheses. ${ }^{*},{ }^{*}$, and $* * *$ indicate statistical significance at the $10 \%, 5 \%$, and $1 \%$ level, respectively. $\dagger$ indicates that the relationship is constrained to be equal to zero. Variables are Churn, Job Creation (JC), Job Destruction (JD), CPS Median Earnings, Employment (Emp), and Price Level. 
Table E19: Small Model Plus GDP, No Parameter Restrictions, Using CPS Median Earnings

\begin{tabular}{rllllll}
\hline \hline & \multicolumn{5}{c}{ Effect of: } \\
\cline { 2 - 7 } Effect on: & Churn & JC & JD & Earnings & Emp & GDP \\
\hline Churn & $0.866^{* * *}$ & 0.054 & -0.157 & 0.058 & $-0.016^{* * *}$ & $1.636^{* * *}$ \\
& $(0.119)$ & $(0.298)$ & $(0.192)$ & $(0.038)$ & $(0.005)$ & $(0.538)$ \\
JC & $0.165^{* * *}$ & $0.247^{*}$ & 0.056 & 0.030 & $-0.012^{* * *}$ & $0.688^{* *}$ \\
& $(0.059)$ & $(0.149)$ & $(0.096)$ & $(0.019)$ & $(0.002)$ & $(0.270)$ \\
JD & -0.051 & -0.062 & $0.391^{* * *}$ & -0.016 & $0.010^{* * *}$ & -0.409 \\
& $(0.084)$ & $(0.212)$ & $(0.136)$ & $(0.027)$ & $(0.003)$ & $(0.383)$ \\
Earnings & -0.249 & 0.473 & $0.749^{*}$ & $0.632^{* * *}$ & 0.011 & -0.574 \\
& $(0.251)$ & $(0.629)$ & $(0.405)$ & $(0.081)$ & $(0.010)$ & $(1.137)$ \\
Emp & $3.495^{* *}$ & 4.161 & -0.706 & -0.369 & $0.625^{* * *}$ & $19.067^{* * *}$ \\
& $(1.598)$ & $(4.014)$ & $(2.583)$ & $(0.517)$ & $(0.066)$ & $(7.252)$ \\
GDP & $0.048^{*}$ & 0.051 & -0.050 & 0.011 & -0.001 & $0.706^{* * *}$ \\
& $(0.027)$ & $(0.069)$ & $(0.044)$ & $(0.009)$ & $(0.001)$ & $(0.125)$ \\
\hline
\end{tabular}

Notes: Standard errors in parentheses. ${ }^{*},{ }^{* *}$, and ${ }^{* * *}$ indicate statistical significance at the $10 \%, 5 \%$, and $1 \%$ level, respectively. $\dagger$ indicates that the relationship is constrained to be equal to zero. Variables are Churn, Job Creation (JC), Job Destruction (JD), CPS Median Earnings, Employment (Emp), and GDP. 
Table E20: Small Model Plus GDP, with Parameter Restrictions, Using CPS Median Earnings

\begin{tabular}{rllllll}
\hline \hline & \multicolumn{7}{c}{ Effect of: } \\
\cline { 2 - 7 } Effect on: & Churn & JC & JD & Earnings & Emp & GDP \\
\hline Churn & $0.850^{* * *}$ & $0^{\dagger}$ & $0^{\dagger}$ & $0^{\dagger}$ & $-0.012^{* * *}$ & $1.254^{* * *}$ \\
& $(0.086)$ & $(0)$ & $(0)$ & $(0)$ & $(0.003)$ & $(0.459)$ \\
JC & $0.178^{* * *}$ & $0^{\dagger}$ & $0^{\dagger}$ & $0^{\dagger}$ & $-0.010^{* * *}$ & $0.562^{* * *}$ \\
& $(0.038)$ & $(0)$ & $(0)$ & $(0)$ & $(0.001)$ & $(0.201)$ \\
JD & $0^{\dagger}$ & $0^{\dagger}$ & $0.488^{* * *}$ & $0^{\dagger}$ & $0.004^{* * *}$ & $0^{\dagger}$ \\
& $(0)$ & $(0)$ & $(0.069)$ & $(0)$ & $(0.001)$ & $(0)$ \\
Earnings & $0^{\dagger}$ & $0^{\dagger}$ & $0.814^{* * *}$ & $0.645^{* * *}$ & $0^{\dagger}$ & $0^{\dagger}$ \\
& $(0)$ & $(0)$ & $(0.249)$ & $(0.070)$ & $(0)$ & $(0)$ \\
Emp & $4.521^{* * *}$ & $0^{\dagger}$ & $0^{\dagger}$ & $0^{\dagger}$ & $0.632^{* * *}$ & $17.826^{* *}$ \\
& $(1.288)$ & $(0)$ & $(0)$ & $(0)$ & $(0.041)$ & $(6.947)$ \\
GDP & $0.055^{* *}$ & $0^{\dagger}$ & $0^{\dagger}$ & $0^{\dagger}$ & $0^{\dagger}$ & $0.606^{* * *}$ \\
& $(0.022)$ & $(0)$ & $(0)$ & $(0)$ & $(0)$ & $(0.114)$ \\
\hline
\end{tabular}

Notes: Standard errors in parentheses. ${ }^{*},{ }^{* *}$, and $* * *$ indicate statistical significance at the $10 \%, 5 \%$, and $1 \%$ level, respectively. $\dagger$ indicates that the relationship is constrained to be equal to zero. Variables are Churn, Job Creation (JC), Job Destruction (JD), CPS Median Earnings, Employment (Emp), and GDP. 